\title{
Folding during soft-sediment deformation
}

\author{
G.I. Alsop ${ }^{1}$, R. Weinberger ${ }^{2,3}$, S. Marco ${ }^{4}$, T. Levi' ${ }^{2}$. \\ 1) Department of Geology and Petroleum Geology, School of Geosciences, \\ University of Aberdeen, Aberdeen, UK. (e-mail: Ian.Alsop@abdn.ac.uk) \\ 2) Geological survey of Israel, Jerusalem, Israel. \\ 3) Department of Geological and Environmental Sciences, Ben Gurion University of the Negev, Beer Sheva, Israel. \\ 4) Department of Geophysics, Tel Aviv University, Israel.
}

\section{Abstract}

The detailed analysis of folding in rocks was in part pioneered by John Ramsay and resulted in a range of techniques and criteria to define folds. Although folding of unlithified or 'softsediments' is typically assumed to produce similar geometries to those in 'hard rocks', there has to date been little detailed analysis of such folds. The aim of this paper is therefore to investigate folds developed during soft-sediment deformation (SSD) by applying techniques established for the analysis of tectonic folds during hard rock deformation (HRD). We use the late-Pleistocene Lisan Formation exposed around the Dead Sea as our case study, as the laminated lake sediments record intricacies of fold detail generated during seismicallytriggered slumping of mass transport deposits (MTD's) towards the depocentre of the basin. While it is frequently assumed that folds created during SSD are chaotic and form disharmonic structures, we provide analyses that show harmonic fold trains may form during slumping, although larger upright folds cannot be traced for significant distances and are more typically disharmonic. Our analysis also reveals a range of fold styles, with more competent detrital-rich layers displaying buckles (Class 1B) as well as upright Class 1A folds marked by thickened limbs. Class $1 \mathrm{~A}$ buckle folds are generally considered to be created by flattening that overprints folds with original Class 1B geometry. As thickened fold limbs are truncated by overlying erosive surfaces, the vertical flattening is considered to have occurred during the slump event. Different fold shapes may partially reflect variable flattening, depending on the original orientation of upright or recumbent folds, together with continued downslope-directed simple shear deformation that modifies the fold geometry. Analysis of fold wavelength, amplitude and bed thickness allows us to plot strain contour maps, and indicates that beds defining slump folds display viscosity contrasts in the range of $50-250$, which are similar to values estimated from folds created during HRD in metamorphic rocks. A range of refold patterns, similar to those established by John Ramsay in metamorphic rocks, are observed within slumps, and are truncated by the overlying sediments indicating that they formed during a single progressive slump event rather than distinct 'episodes' of superimposed deformation. This study confirms that techniques developed for the analysis of folds created during HRD are equally applicable to those formed during SSD, and that resulting folds are generally indistinguishable from one another. Extreme caution should therefore be exercised when interpreting the origin of folds in the rock record where the palaeogeographic and tectonic contexts become increasingly uncertain thereby leading to potential misidentification of folds created during SSD.

Keywords: folding, slumps, mass transport deposit, Dead Sea 
It is generally assumed that slump folds generated during soft-sediment deformation (SSD) within mass transport deposits (MTDs) bear a close resemblance to tectonic folds created during hard rock deformation (HRD) (see discussions in Elliot \& Williams 1988; Maltman 1994; Alsop et al. 2019a). However, there has in reality been very little systematic analysis of fold styles created during soft-sediment deformation, with some notable exceptions including Woodcock (1976a, b, 1979), Farrell \& Eaton (1987), Waldron \& Gagnon (2011) and Ortner \& Kilian (2016). Hudleston (1986, p.238) noted that "shape alone cannot be used to distinguish soft-sediment folds from tectonic folds" (see also Woodcock 1976b). Comparison of curvilinear fold patterns in metamorphic rocks and soft-sediments also reveals no significant geometric difference between aspects of curvilinear fold geometries (e.g. Alsop et al. 2007).

While folding within metamorphic rocks is generally created by deformation associated with recrystallization, folding within unlithified or 'soft sediments' is typically achieved via independent particulate flow, where individual grains move relative to one another to create a range of structures (e.g. Knipe 1986). The exact nature of these structures is dependent on the ratio of pore fluid pressure to cohesive strength of the sediment (e.g. Knipe 1986; Ortner 2007), with folds and shears being created where fluid pressure is less than cohesive strength leading to hydroplastic deformation. The examination of fold geometries is important as Waldron \& Gagnon (2011) realised that fold styles in different sand and mud layers may be used to distinguish the degree of lithification during the fold process, and thereby identify 'soft-sediment' folds. Despite the obvious differences in the mechanisms of folding within HRD and SSD noted above, the geometry of the resulting structures are so similar to one another that criteria to distinguish between these different types of folds in ancient settings should be considered (see Alsop et al. 2019a for a review).

The broad aim of this contribution is to document and investigate fold styles created during SSD by applying classical techniques of structural geology such as dip-isogon analysis and examination of fold interference patterns established by John Ramsay among others (e.g. Ramsay 1967, Ramsay \& Huber 1987). Van der Pluijm \& Marshak (2004, p.25) discuss slump folds and note that "folds in one layer are of a different size and orientation than the structures in adjacent layers" suggesting a largely disharmonic style. We therefore examine trains of soft-sediment folds to determine whether they are indeed disharmonic using techniques of fold spacing compared to distance they can be traced along their axial surface (e.g. Twiss \& Moores 2007, p.290). We also analyse folded layer thickness, amplitude and wavelength in an attempt to estimate the viscosity contrast between layers during sediment folding together with \% shortening (e.g. Schmalholz \& Podladchikov 2001). Our analysis aims to help answer the following research questions.

i) Does slumping create harmonic or disharmonic folds?

ii) Are refold patterns in slumps similar to those in metamorphic rocks?

iii) What range of fold styles are created during slumping?

iv) How are slump folds subsequently modified?

v) Are estimates of viscosity contrasts in slumps folds similar to those in metamorphic rocks? 
We first describe the regional setting of the case study area in the Dead Sea Basin, before analysing folds created during SSD linked to downslope-directed slumping of MTDs towards the basin.

\section{Regional setting}

The Dead Sea Basin is a pull-apart structure on the Dead Sea Fault, which is marked by two major parallel fault strands that generate numerous earthquakes (Fig. 1a, b) (e.g. Marco et al. 1996, 2003; Ken-Tor et al. 2001; Migowski et al. 2004; Begin et al. 2005). This transform is thought to have been active from the Miocene to recent, including during deposition of the Late Pleistocene (70-15 Ka) Lisan Fm. that forms the focus of the present study (e.g. Bartov et al. 1980; Garfunkel 1981; Haase-Schramm et al. 2004). The Lisan Fm. comprises mm-scale aragonite laminae that were precipitated from the upper waters of Lake Lisan during the summer, together with more detrital-rich layers washed into the lake during flood events (Begin et al. 1974) (Fig. 2a, b). The detrital units have been sampled $<1 \mathrm{~km} \mathrm{NE}$ of the Peratzim site by Haliva-Cohen et al. (2012) (see Fig. 1b), and compositionally consist of quartz and calcite grains with minor feldspar, and clays (illite-smectite). Detrital laminae within the varved aragonite-rich Lisan Fm. display grain sizes of $\sim 8-10 \mu \mathrm{m}$ (silt), while the thicker $(>10 \mathrm{~cm})$ detrital-rich units are generally coarser grained $(60-70 \mu \mathrm{m})$ and can be classified as very fine sands (Haliva-Cohen et al. 2012). Although deposited on slopes of $<1^{\circ}$, the Lisan Fm. contains numerous intraformational fold and thrust horizons that are capped by undeformed beds and are considered to be seismically triggered (Alsop \& Marco 2013; Alsop et al. 2016; Lu et al. 2017) (Fig. 2a). Some evidence for bedding parallel shear during seismic events is also preserved by offset clastic dykes (Weinberger et al. 2016).

The Lisan Fm. is exposed for $\sim 100 \mathrm{~km}$ along the western margin of the Dead Sea Basin and displays systematic variation in the orientation of slump fold and thrust systems within it. In the northern portions slumping is directed towards the ESE, in the central portion around Masada slumping is towards the east, whilst in the southern area around Peratzim slumping is NE-directed (Alsop \& Marco 2012a) (Fig. 1b). Combined with westerly directed slump folds recorded from the eastern shore of the Dead Sea in Jordan (El-Isa \& Mustafa 1986), this suggests a regional pattern of radial slumping towards the depocentre of the Dead Sea Basin (Alsop \& Marco 2012a). In the extreme southern area around Zin, slumping is towards the south and is interpreted to be influenced by the nearby NE-SW trending Amazyahu Fault (Weinberger et al. 2017, Alsop et al. 2018; 2019b) (Fig. 1b). This overall pattern has been subsequently corroborated by Anisotropy of Magnetic Susceptibility (AMS) fabrics that support a radial pattern of MTD slumping (Weinberger et al. 2017).

The Dead Sea Basin is an ideal place to study structures associated with SSD as the relatively cohesive muds and precipitated aragonitic layers define an intricate varve-like stratigraphy that define a range of detailed structures that may not survive elsewhere (Fig. 2a, b). The MTD horizons and reworked zones of sediment we are particularly interested in for this case study are best exposed around Masada [N31 ${ }^{\circ} 1847.0$ E35 2228.3 ], Peratzim $\left[\mathrm{N} 31^{\circ} 0449.6 \mathrm{E} 35^{\circ} 2104.2\right]$, and $\operatorname{Zin}[\mathrm{N} 31.00615, \mathrm{E} 35.26342]$ in the central and southern Dead 
Sea areas respectively (Fig. 1b) (see Weinberger et al. 2017). All of these sites are positioned $\sim 1 \mathrm{~km}$ east of the Dead Sea western border fault zone, with Cenomanian-Senonian carbonates preserved further to the west in the footwall to this fault. For most of the time between 70 and 28ka, Lake Lisan in these areas had a maximum depth of $100 \mathrm{~m}$ or less, apart from a brief period from 26-24 ka when water was up to $200 \mathrm{~m}$ deep (Bartov et al. 2003).

\section{Analysis of slump fold and thrust displacement}

Six individual slump sheets that form MTDs have been recognised in the Peratzim area (Alsop et al. 2016). Although some variability exists, slump fold hinges are typically NW-SE trending and verge and face towards the NE, with transport directed towards the depocentre of the basin (Alsop et al. 2016) (Fig. 2c-h). Fold axial planes dip variably towards the SW, while downslope-verging fore thrusts dip towards the SW (Fig. 2c-h) (Alsop et al. 2017a). At the Masada locality, fold hinges are typically NNW-SSE trending with gently WSW dipping axial planes and overall ENE-directed vergence with transport towards the depocentre of the basin (Alsop \& Marco, 2012a) (Fig. 3a, b). At the Zin locality, fold hinges are E-W trending and typically verge and face towards the south (Weinberger et al. 2017; Alsop et al. 2018). As with previous studies, care has been taken that cuttings along wadi walls are developed at high angles to fold hinges, thereby providing transport-parallel (or hinge-normal) profile sections to undertake structural analysis (e.g. Alsop et al. 2017b).

Each MTD horizon is overlain by undeformed sediments that were deposited after each slope failure event (e.g. Fig. 2a). The tops of MTDs, and the folds they contain, may be truncated by the overlying sedimentary 'cap' that was deposited out of suspension following the failure event (Alsop \& Marco 2012b, Alsop et al. 2016, 2019a, b). This cap, which may be up to $20 \mathrm{~cm}$ thick, blankets and infills the underlying slump topography, and demonstrates that the structures formed at or close to the sediment surface. The studied sections form in the upper part of the Lisan Fm. and have never had significant overburden $(<10 \mathrm{~m})$ above them. As such, the structures created during slumping have not undergone significant later modification, and preserve pristine geometries unmodified by later compaction (Alsop et al. 2017a, b, 2019a). In addition, the aragonite- and detrital-rich alternations within the Lisan Fm. form a bilaminate sequence i.e. "comprising only two different types of layers which alternate with each other" (Price \& Cosgrove 1990, p.307). Such bilaminates simplify the analysis of folding, although they need not be regularly spaced (equal thickness) and may form either multilayer packages of folding (where folding is closely spaced) or single layer buckles where competent beds are separated from one another by a weaker 'host'.

\section{Harmonic and disharmonic slump folding}

A harmonic fold is simply defined as being continuous along its axial surface for 'many multiples of the half wavelength' whereas a disharmonic fold 'dies out within a couple of half wavelengths' (Twiss \& Moores 2007, p.289; see also Fossen 2016 p.259). The half wavelength may be approximated by the spacing (S) of adjacent axial surfaces, while the 
continuity of the axial surface may be directly measured (D), to produce a ratio $(\mathrm{H})$ which is equivalent to D/S (see Twiss \& Moores 2007, p.290) (Fig. 3a).

Upright folds within the Lisan Fm. are frequently disharmonic, as they are positioned above basal detachments and are overlain by sedimentary caps meaning that they cannot be traced for any significant distance (D) along their axial surfaces (e.g. Fig. 2c, e, g). However, we have also analysed trains of recumbent slump folds (Fig. 3a, e, i). In general the maximum distance (D) that individual decimetric-scale folds may be traced along their axial planes increases as the maximum spacing ( $\mathrm{S}$ ) between adjacent axial planes becomes greater (Fig. $3 \mathrm{a}, \mathrm{c})$. In addition, the ratio $\mathrm{H}(\mathrm{D} / \mathrm{S})$ ranges from $\sim 18$ to $\sim 6$, and is shown to reduce in a nonlinear way as $\mathrm{S}$ increases (Fig. 3d). Analysis of individual fold systems reveals broadly similar patterns of D, S, and resulting H (Fig. 3e-1). Individual fold packages may form en echelon fold trains that migrate up through the folded sequence where they cross thicker aragonite-rich units (Fig. 3a). These fold packages do not directly interact with one another and do not therefore create refold patterns (see section 5) below). Overall, these recumbent folds may be described as broadly harmonic as $\mathrm{D}>>\mathrm{S}$.

\section{Refold patterns within individual slump horizons}

Working on polyphase deformed metamorphic rocks in the Scottish Highlands, Ramsay (1962, 1967 p.518) developed a classification scheme of refolded folds, based on the relative orientations of different sets of fold hinges and axial surfaces that were superimposed on one another and considered to develop sequentially during orogenesis. Ramsay's $(1962,1967)$ classic Loch Monar dam outcrops comprise superb water-washed exposures in psammites of the Precambrian Moine Supergroup, and permit intricate details of folding to be examined (e.g. Fig. 4a). Ramsay (1967 p.521) recognised Type 1 or 'dome and basin' refold patterns created by superimposition of fold hinges and axial planes at high angles $\left(\sim 90^{\circ}\right)$ to one another (Fig. 4b, c). Type 2 crescent or 'angel-wing/ mushroom' styles of refolding formed by superimposition of fold hinges and axial planes at moderate to high angles to one another were also observed (Ramsay 1967, p.525), as where Classic Type 3 'hook' refolds that form where superimposed fold hinges are coaxial, while axial surfaces are at high angles to one another (Ramsay 1967, p.530) (Fig. 4d). This general classification scheme has subsequently been applied across a huge range of metamorphic rocks, scales and settings.

Within the Peratzim area of the Dead Sea case study (Fig. 1b), Type 1 or 'dome and basin' refold patterns are developed in wadi sections within individual MTDs (Fig. 4e, f). Type 2 crescent or 'angel-wing/ mushroom' styles of refolding are also observed (Fig. 4g) as are classic Type 3 'hook' refolds that are particularly common (Fig. 4h, i, j). Refold patterns are truncated by the overlying sedimentary cap that was deposited from suspension following the slump event (Alsop \& Marco 2012b) (e.g. Fig. 4j). This indicates that refolding was completed during the slump event and was not a much later re-working created via subsequent loading or later slumping. Thus, a re-working or modification of folds to create classic refold patterns occurs during a single, progressive slump event. 


\section{Dip-isogon analysis around slump folds}

The dip-isogon method is a well-established technique of fold classification in lithified rocks developed by John Ramsay (e.g. Ramsay 1967, p.363). In this method, dip isogons join points of equal dip on adjacent folded surfaces within the fold profile, $\mathrm{t}_{0}$ is layer thickness measured along the axial surface, while $t_{\alpha}$ is orthogonal layer thickness measured at various angles ( $\alpha$ - alpha) to the reference plane (Fig. 5a). Graphs normalise thicknesses by using $\mathrm{t}^{\prime} \alpha$ (where $\mathrm{t}^{\prime}{ }_{\alpha}=\mathrm{t}_{\alpha} / \mathrm{t}_{0}$ ) and plot this value against dip angle $(\alpha)$ to create a series of fold classes (Ramsay 1967, p. 366). Class 1 folds are marked by convergent dip isogons (Fig. 5b), Class 2 folds by parallel dip isogons (Fig. 5c), and Class 3 folds by diverging dip isogons (Fig. 5d) (e.g. Ramsay 1967, p.365; see Fossen 2016, p.263).

We use the dip-isogon method to analyse and compare fold geometries formed in aragonite-rich and detrital-rich units within the case study at Peratzim (Fig. 1b). The unlithified sediment enables easy excavation, and reveals that E-W trending asymmetric buckle folds with gently south-dipping axial planes verge towards the north (Fig. 5 e, f, g). Our analysis includes data from both the upper and lower limbs of folds, and shows that folds within aragonite-rich units display gently convergent to parallel dip isogons that typically define Class 1C folds (Ramsay 1967, p.367; Fossen 2016, p.263) (Fig. 5h, i). Conversely, the detrital units are marked by a strongly convergent isogon pattern representing Class 1C or $1 \mathrm{~B}$ parallel folds consistent with buckling (Fig. 5h, i). In detail, the upper limbs are in part Class 1C (Fig. 5h, i), while the lower overturned limb may exhibit a component of thickening relative to the hinge area to create Class $1 \mathrm{~A}$ folds (Fig. 5h, i, 6a, b). However, as folds become progressively more asymmetric and overturned, the lower limb is consequently thinned (Fig. 5e). These overturned buckles also display a reduction in the angle of axial planar dip from $70^{\circ}$ to $24^{\circ}$, together with a slight re-orientation of fold hinges from $092^{\circ}$ towards $063^{\circ}$ and the general slope direction at Peratzim (Fig. 2c-h, 5e,f,g). In general, more upright folds within detrital-rich units display Class 1A or Class 1B (parallel) buckle fold styles, while recumbent folds are marked by Class 1C or Class 2 (similar) geometries (Fig. 6a-h). Aragonite-rich units generally display a parallel isogon pattern most consistent with Class 2 similar folding (Fig. 6c, d, g, h). These relationships collectively indicate that detritallayers were locally more competent (see also Alsop et al. 2017a, b), and suggest that folding involved a component of progressive deformation that resulted in tightening and rotation of fold hinges towards the flow direction, while axial planes were rotated into the plane of flow.

Ramsay (1967 p.432) recognised that multilayers folds may be composed of adjacent beds defining different classes of folds such as Class $1 \mathrm{C}$ in more competent units and Class 3 in the incompetent horizons, although the overall fold represent the sum of these layers and will closely resemble a Class 2 similar fold. Within individual folds of the Lisan Fm., different layers define different classes of fold, with aragonite-rich layers displaying Class 2 (similar) folds, while adjacent detrital-rich beds are marked by Class $1 \mathrm{C}$ fold geometries (Fig. $6 \mathrm{~g}, \mathrm{~h})$. Such varying styles of folding allow an individual fold to propagate further along its axial plane without encountering significant accommodation problems around the fold hinge (e.g. Price \& Cosgrove 1990, p.320). 


\section{Post-buckle modification of slump folds}

Buckling is simply defined as "the flexing or folding of a surface or series of parallel surfaces by a compressive stress directed along that surface or layer" (Price \& Cosgrove 1990, p.273). However, Ramsay (1967, p.434) also recognised that buckle folds may undergo subsequent deformation and flattening that transforms their geometry from typical Class 1B parallel folds to Class $1 \mathrm{C}$ or Class 2 (similar) folds. A simple technique to determine the amount of postbuckle flattening was developed by Lisle (1992), and uses the inverse thickness method, where $t$ is the orthogonal thickness measured between two tangents for the inner and outer layer boundaries. The inverse layer thickness $(1 / \mathrm{t})$ is then plotted for various orientations of the layer tangent around the fold (see Lisle 1992, p.370) (Fig. 7a, b). This method has the significant advantage that post-buckle flattening does not have to be aligned parallel to the axial trace of the buckle fold (Lisle 1992). Although this technique was devised and applied to folds formed during HRD (e.g. Lisle 1992; Alsop et al. 1998, their fig. 7), the present study forms its first use on folds created during SSD. Within the study area, elliptical ratios using the method of Lisle (1992) range between 1.77 (Fig. 7a, b), 1.70 Fig. 7e, f), 1.97 Fig. 7i, j), suggesting a relative vertical shortening and flattening of $\sim 30 \%$.

Within the Lisan Fm., folding of detrital-rich marker layers that are more competent than surrounding aragonite-rich horizons (e.g. Alsop et al. 2017a, b) results in a parallel (Class 1B) style of folding (Fig. 5h,i). The flattening of upright Class 1B folds by vertical shortening results in thicker limbs compared to hinges (Class 1A) (Figs. 6a,b, 7a-1), whereas potential vertical flattening of recumbent horizontal folds results in limbs becoming thinner (relative to hinges) and creation of Class 1C or similar (Class 2) folds (Fig. 6c-h) (see Farrell \& Eaton 1987, their figure 11). Examples of both types of folds defined by detrital-rich marker horizons that are originally considered to have formed Class $1 \mathrm{~B}$ folds are observed in the Lisan Fm. (Fig. 6c-h). Clearly, the post-buckle flattening component is independent of the orientation of the buckle fold, with the orientation of the strain ellipse indicating that flattening was consistently sub-vertical (Fig. 7a-l). The thickening and thinning patterns observed around the slump folds are similar to the theoretical models of flattened folds as discussed by Twiss \& Moores (2007, p.374).

An elegant development to the model of Lisle (1992) was provided by Srivastava \& Shah (2006) who realised that strain ellipses (and the associated photograph of the fold) may simply be 'unstrained' on drafting packages by restoring the calculated strain ellipse back to an original circle i.e. Fig. $7 \mathrm{a}$ and $7 \mathrm{~b}$ are transformed to Fig $7 \mathrm{c}$ and $7 \mathrm{~d}$ respectively when 'unstrained' (Fig. 7a-1). The upslope and downslope limbs have slightly different ellipse shapes and this perhaps reflects the original limb thicknesses that vary as a result of fold vergence downslope towards the depocentre. The observation that upright Class $1 \mathrm{~A}$ folds with thickened fold limbs are developed close to the sediment surface and are truncated by the overlying sedimentary cap (Fig. 7i-1) demonstrates that flattening formed during the actual slump event, and is not a later effect created by loading from overlying MTDs.

\section{Analysis of layer thickness, amplitude and wavelength in slump folds}


Layer thickness (h), amplitude $(A)$ and wavelength $(\lambda)$ of single layer folds (rather than multi layers) may be measured in an attempt to estimate the strain and viscosity contrast between layers during folding (e.g. Schmalholz \& Podladchikov 2001; see also Hudleston \& Treagus 2010). The technique involves analysis of single layer folds (i.e. unaffected by neighbouring competent beds) and is based on results for linear viscous folding rather than power law viscous folding (Schmalholtz \& Podladchikov 2001). Thickness of a layer (h) is measured orthogonal to the folded layer, while amplitude $(A)$ is defined as half the distance from the trough to the crest of upright folds (e.g. Fig. 8a). Wavelength $(\lambda)$ is defined as the distance between two points that occupy a similar position on the fold train (i.e. between adjacent synform hinges) (e.g. Fig. 8a). Schmalholz \& Podladchikov (2001, p. 206) state that wavelength may also be measured as double the horizontal distance between neighbouring fold hinges (i.e. double the distance between antiform and synform fold hinges forming a fold pair). In this method of fold analysis, amplitude / wavelength $(A / \lambda)$ is compared with layer thickness / wavelength $(\mathrm{h} / \lambda$ ) on a strain contour map (Schmalholz \& Podladchikov 2001). For any fold where amplitude, thickness and wavelength can be measured on the profile plane, estimates of bulk strain (in terms of \% shortening) and the layer / matrix viscosity ratio can be made by reading the position of data directly off the map (e.g. Fig. 8a-r). This study forms the first use of this methodology in folds created during SSD, and assumes all the layer shortening is taken up by buckling with no out of plane movement.

Within individual fold trains, wavelength of folds $(\lambda)$ reduces as amplitude $(A)$ increases, so that the $A / \lambda$ ratio defines a general trend when plotted against $\lambda$ (Fig. $8 \mathrm{a}-\mathrm{b}, \mathrm{d}-\mathrm{e}$, $\mathrm{g}-\mathrm{h}, \mathrm{j}-\mathrm{k}, \mathrm{m}-\mathrm{n}, \mathrm{p}-\mathrm{q})$. In detail, when compared to wavelength, the $A / \lambda$ ratio is not a straight line, with amplitude increasing more slowly than wavelength (Fig. 8e). In general, steeper folds typically have lower $A / \lambda$ ratios, as recumbent folds can develop proportionally greater amplitudes due to being unconstrained and unhindered by the overlying sediment surface (e.g. compare upright folds in Fig.8g, h with recumbent folds in Fig. 8p, q). The higher $A / \lambda$ ratios of recumbent folds may also be a product of increased simple shear, which rotates the axial plane towards the shear plane (e.g. Fig. 5e,f,g, 8a-c). Overall analysis of individual fold data sets on the strain contour maps (Schmalholz \& Podladchikov 2001) reveals that most folded layers display viscosity contrasts in a range between 50 and 250, while calculated layer shortening is generally between $30 \%$ and $70 \%$, (Fig. $8 \mathrm{c}, \mathrm{f}, \mathrm{i}, 1, \mathrm{o}, \mathrm{r}$ ). Within individual fold trains, $\%$ contraction typically increases as folds become more inclined, or recumbent (e.g. Fig. 8a-c), with some small-scale recumbent folds recording values in excess of $70 \%$ (e.g. Fig. 8p-r). When plotted on strain contour maps, the overall trends of data from individual fold trains are slightly oblique to the established lines marking fixed viscosity contrasts, with some plots suggesting folds with lower \% shortening are marked by lower viscosity contrasts compared to folds with higher \% shortening (Fig. 8c). In other more typical cases, folds with lower $\%$ shortening have greater viscosity contrasts compared to adjacent folds with higher \% shortening, resulting in more 'gentle' trends on strain contour maps (Fig. 8f, i, 1, o).

When the combined data set is considered, amplitude $(A)$ shows a clear correlation with wavelength $(\lambda)$ across a range of scales from mm (Fig. 9a), to cm (Fig. 9b) to larger folds shown on log-log plots (Fig. 9c). Similarly, layer thickness (h) and fold wavelength $(\lambda)$ 
increase in tandem and correlate across a range of scales from $\mathrm{mm}$ to $\mathrm{m}$ (Fig. 9d-f), as do layer thickness (h) and fold amplitude (A) (Fig. 9g,h). These general correlations produce a cluster of points on the overall strain contour plot, suggesting viscosity contrasts in the range of 50-250, and \% shortening between 30 and $70 \%$ (Fig. 9i).

\section{Discussion}

\section{Does slumping create harmonic or disharmonic folds?}

Our results demonstrate that the distance (D) fold trains can be traced along their axial surfaces, compared to the spacing (S) with the neighbouring axial surface show distinct and consistent relationships (Fig. 3c, g, k). The ratio $\mathrm{H}(\mathrm{D} / \mathrm{S}$ ) varies between $\sim 6$ and 18 , and generally increases as the spacing (S) reduces (Fig. 3d, h, i). These relationships collectively demonstrate that overturned and recumbent slump folds that can be traced for $<1 \mathrm{~m}$ display harmonic fold relationships (Figs. 3, 10). Price \& Cosgrove (1990 p.307) suggest that the development of harmonic or disharmonic folds is dependent on the spacing of the competent beds, and suggest that "adjacent layers must be closer than the sum of their dominant wavelengths (perhaps as little as $10 \%$ of this distance) before they will buckle harmonically". Numerical modelling of linear viscous multilayer folding by Schmalholtz \& Mancktelow (2016, p. 1436) also indicates that more closely spaced layering may display 'contact strain' and will tend to fold harmonically. An inspection of Fig. 3a reveals that the more competent detrital-rich markers are indeed typically closely spaced relative to fold wavelength, and therefore supports this general model.

The observation that individual fold packages die out both up and down their axial surface (with associated reductions in spacing of neighbouring axial surfaces) suggests that folds nucleated in the central area of each fold package and then propagated both upwards and downwards (Fig. 3a). Packages of en echelon folding generally transfer upwards through the slumped unit, with 'jumps' in each en echelon fold package typically occurring across thicker aragonite-rich units (Fig. 3a). Neighbouring en echelon systems tend to transfer across the same stratigraphic level marked by the weaker aragonite units (Fig. 3a), suggesting that they may form easy-slip horizons and thereby control the position and geometry of fold trains. Although en echelon segments are broadly parallel, there is a general reduction in axial surface dip together with interlimb angles up through the deformed sequence, such that the uppermost fold packages comprise sub-horizontal tight-isoclinal folds (Fig. 3a). This may suggest increasing shear towards the sediment surface during downslope-directed progressive deformation (Alsop \& Marco 2013). The larger fold trains are preserved in the centre of the slump, perhaps indicating that deformation initiated here, and then transferred downwards towards the underlying basal detachment. Such patterns are similar to that encountered within thrusts of the Lisan Fm., where larger displacement may occur on thrust ramps that initiated above the basal detachment (Alsop et al. 2017a). 
Within orogenic belts, refold patterns were originally considered to be created by punctuated episodes of overprinting deformation. Each deformation 'phase' was considered to have a distinct style and orientation that were correlated over large distances within metamorphic rocks, and resulted in refold patterns where fold phases interfered with one another (see discussion in Fossen 2016, p.456; Fossen et al. 2019). The strict adherence to such 'Dnumber' schemes started to break down with the realisation that heterogeneous strain could produce variable styles and orientations of structures during single progressive deformation events associated with orogenesis (e.g. Coward \& Potts 1983, Holdsworth 1990; Alsop \& Holdsworth 1993).

A similar range of refold geometries may be produced within slumps as observed in metamorphic rocks (e.g. Tobisch 1984; Farrell \& Eaton 1987), although refolds within slumps form within a single slump event created by slope failure (Fig. 4a-j). Refolding that produces coaxial interference marked by Type 3 'hook' patterns may be associated with consistent directions of flow, and a late phase of pure shear shortening that was superimposed as the slump motion reduced or stopped (Farrell \& Eaton 1987). Alternatively, non-coaxial refolding marked by Type 1 'dome and basin' or Type 2 'mushroom' refolds implies either that the flow direction is not constant within the slump, or differential shear has locally developed within a broadly uniform slump direction leading to the creation and re-working of variably oriented folds within the flow perturbation (e.g. Alsop \& Holdsworth 1993). There is no evidence within the case study that refolds are created during later loading of the slump by overburden, as the refolds are themselves truncated by erosive surfaces associated with deposition of the overlying sedimentary cap (Figs. 4j, 10). Some reworking of slump folds linked to 'relaxation' and reorganisation of the MTD may locally develop and have been described by Alsop \& Marco (2011, p.449). There is also some evidence that refolding of slump folds developed within $<10 \mathrm{~cm}$ of the sediment surface may be created by the movement of the overlying water column as it 'sloshes' back and forth across the narrow basin during seiche events (Alsop \& Marco 2012b). However, overall energy within the gravity-driven MTD will generally dissipate after the initial seismic trigger and the resulting downslope movement. In summary, the observation that a similar range of refold styles may be created by slump folds during SSD, compared to metamorphic folds formed during HRD, demonstrates that progressive deformation is a valid mechanism to generate such interference patterns irrespective of setting.

\section{What range of fold styles are created during slumping?}

This study has shown that all potential fold styles ranging from Class 1A, 1B, 1C, Class 2 and Class 3 may form within slump systems (Figs. 5a,i, 6a-h). The development of more parallel folds (Class 1B) in competent layers, and Class 3 folds in adjacent weaker layers (e.g. Fig. 6g,h) may combine to create overall similar fold packages that "can extend for a significant distance in the profile section, in a direction parallel to the axial plane" (Price \& Cosgrove 1990, p.316). Different alternating fold styles in the bilaminate (e.g. Fig. 6g, h) may therefore encourage harmonic folding. Ortner \& Kilian (2016) also recognised fold styles that vary between Class 1B and Class 3 in adjacent layers within unlithified carbonates undergoing downslope-directed creep. Ramsay (1974) realised that if competent layers were thicker than the average in the multilayer, then accommodation structures must develop 
around this thicker layer, with adjacent layers displaying 'keel-like' hinges (Price \& Cosgrove 1990, p.320). Similar structures are observed in fold hinges formed next to thicker detrital layers in the present study (e.g. Fig. 8p).

Waldron \& Gagnon (2011) suggested that the style and class of folds in different lithological layers may be critical in identifying SSD. Unlithified muds may display buckle folds (Class 1B), while adjacent sands are weaker (due to greater porosity and water content) and may display Class 2 (similar) folds. These relationships in unlithified sediments are the opposite to that typically encountered in lithified rocks, were sandstones are normally more competent than mudstones during folding associated with HRD. Indeed, Hibbard \& Karig (1987, p.848) record Class 1B folds in sandstones and Class 2 or Class 3 folds in mudstones and suggest that beds may have been lithified at the time of folding in a variably deformed accretionary complex in SW Japan. In summary, although folding in unlithified sediments is formed via deformation associated with 'hydroplastic' particulate flow, rather than recrystallization as in metamorphic hard rock deformation (HRD), the range of geometries produced are similar to one another. This includes the development of axial planar fabrics in slump folds as observed previously within the Lisan Fm. (e.g. Alsop \& Marco 2014; Alsop et al. 2019a, b). Different lithologies may however behave more or less competently during HRD or SSD and thereby create folds of distinct styles in each setting.

\section{How are slump folds subsequently modified?}

Post-buckle flattening

Ramsay suggested (1967, p.411) that Class 1B parallel folds may be subsequently modified by 'flattening' that resulted in Class 1C geometries. Ramsay (1967, p.433) went on to suggest that "Many of the apparently similar folds seen in naturally deformed rocks probably owe their initial development to the buckling mechanism". We have therefore undertaken analysis of such post-buckle modification in order to test if this is an appropriate mechanism to create the range of fold styles within the case study. Homogeneous flattening normal to the axial plane of an original Class 1B fold results in an increased fold amplitude and a Class 1C fold (e.g. Farrell \& Eaton 1987, p.193), whereas flattening parallel to the axial plane leads to a reduction in fold amplitude and a Class 1A fold (e.g. Twiss \& Moores 2007, p.374). Hudleston (1973) recognised that Class 1C folds may be produced during simultaneous buckling and flattening, and there is therefore no necessity for separate and sequential 'phases' of fold development, with folds created during progressive deformation within the slump.

Our analysis reveals that if flattening were the sole cause of the different fold styles, then it would need to form a significant element in the deformation. Using the technique of Lisle (1992) described previously, elliptical ratios of $\sim 1.7$ are calculated, suggesting a relative vertical shortening of $30 \%$ (Fig. 7a-d). In other cases, some Class1C folds defined by detritalrich markers would in fact suggest up to $\sim 50 \%$ homogenous shortening (Fig. 7i-1). The 'mismatch' of axial surfaces that 'jump' when traced across weak beds may be a consequence of such flattening (e.g. Fig. 3a). However, recumbent crenulations observed in aragonite laminae 
in the hinges of upright Class1A folds record only limited vertical shortening (see Alsop \& Marco 2011). Such horizontal crenulations were attributed to 'compaction' by Alsop \& Marco (2011). As there is no other evidence for significant flattening, with thrusts preserving pristine dip angles of $30^{\circ}$ (e.g. Alsop et al. 2017a, b), and a complete absence of folded clastic dykes (Alsop et al. 2019a), this amount of vertical shortening seems unfeasible. Postbuckle flattening may represent a small component that affects upright Class $1 \mathrm{~B}$ folds close to the sediment surface where uncompacted sediment was most water-saturated, and results in locally thickened limbs and thinned hinges (Class 1A) (Fig. 10). However, given the lack of supporting evidence, post-buckle flattening should not perhaps be applied to the entire sequence and we therefore suggest that other mechanisms may also have operated to modify fold shapes.

\section{Post-buckle shearing}

The relationship between layer thickness and fold wavelength suggests buckling is the dominant fold mechanism within slump folds of this case study and elsewhere (e.g. Woodcock 1976b; Farrell \& Eaton 1987). As noted above, deviation of buckle folds from Class $1 \mathrm{~B}$ may be a consequence of vertical flattening, creating upright Class $1 \mathrm{~A}$ with thickened limbs (e.g. Figs. 6a,b, 10), or recumbent Class 1C folds with thinned limbs (e.g. Fig. 6c,d) (e.g. Farrell \& Eaton 1987, their figure 11). However, the variation in geometry may also be created by simple shear being imposed on the buckles resulting in thickened or thinned fold limbs depending on the orientation of the fold and amount of shear (e.g. Farrell \& Eaton 1987; see discussion in Twiss \& Moores 2007).

It has previously been suggested that buckle folds within the Lisan Fm. may form during layer-parallel shortening associated with pure shear, and that fold initiation may also potentially involve density-driven flow into antiforms associated with Rayleigh-Taylor instabilities (e.g. Alsop \& Marco 2011, p.453) (Fig. 10). Downslope-directed simple shear is then progressively imposed on these folds to create the observed range of geometries (Alsop \& Marco 2011 p.446) (Fig. 10). The tightening and rotation of upright buckles to overturned folds in the case study (Fig. 5e,f,g) is consistent with increasing downslope-directed noncoaxial dominated deformation (e.g. Woodcock 1976b; Farrell \& Eaton 1987; Twiss \& Moores 2007, p.360; Dasgupta 2008) (Fig. 10). This interpretation is also supported by numerical simulations of downslope-directed gravity sliding that results in buckle folds with hinges that rotate towards the flow direction and axial planes that sequentially rotate into the plane of flow during continued slumping (Schmalholz \& Schmid 2012, p. 1817).

Recumbent folds are sometimes marked by thicker overturned lower limbs compared to the upper fold limbs (e.g. Fig. 3a, 5h,i). Folds with thicker lower limbs suggest that original buckle was upright, and that the downslope limb has spent some time in the contractional field of the strain ellipsoid (while the upslope limb was always in the extensional field and therefore thinner). In other cases, the lower fold limbs are more thinned (Fig. 6g,h), suggesting that these buckles may have originated with a downslope asymmetry with shorter, steeper limbs marking vergence towards the basin (see Alsop \& Marco 2013, 
their fig. 7). The observation that most folds in the case study display thinned lower limbs is consistent with original buckles displaying a downslope-directed asymmetry and vergence towards the basin. In addition, we do not generally observe recumbent Class 1B or upright Class $1 \mathrm{C}$ or Class 2 folds, suggesting that folds are modified as they become overturned during downslope-directed shearing. These observations collectively suggest that slump folds originated as more upright buckles that have been subsequently deformed by downslopedirected simple shear deformation (see Farrell \& Eaton 1987; Alsop \& Marco 2011) (Fig. 10). There may therefore be a combination of post-buckle flattening and shearing, with recumbent Class $1 \mathrm{C}$ being created by flexural flow rather than flattening of original Class $1 \mathrm{~B}$ buckles.

\section{Post-buckle flow}

Price \& Cosgrove (1990, p.402) note that "post-buckle flattening may involve physical migration of the relatively incompetent material". They further note (Price \& Cosgrove 1990, p.403) that incompetent layers in the short limbs of folds may have thinned due to "the migration of material from the limbs to the hinge region in response to stress gradients, which tend to become greater during the last stages of fold amplification". Although our analysis is performed on unlithified detrital-rich beds, these beds are exceptionally weak and capable of flow when compared to lithified rocks.

Within the case study slump folds, some upright synforms are markedly thickened in the hinges when compared to adjacent antiforms (Fig.7e, $8 \mathrm{~m}$ ), while the converse is rarely observed. This suggests that in some cases there may be a component of material flow from the antiformal crest down into the synformal troughs. The typical position of Class 1A folds towards the upper parts of slumps directly below erosive truncation surfaces linked to the sediment water interface, suggests that gravity-driven migration of sediment within steep water-saturated fold limbs close to the surface may be a significant factor (e.g. Figs. 7, 10). Farrell \& Eaton (1987, p.186) examined slump folds in Cyprus and the Spanish Pyrenees and also note "flowage of sediment into cores of folds", which on examination of their figure $3 \mathrm{~d}$ is predominantly towards the troughs of synforms. Flow of sediment down off earlier structural highs and folds was previously termed 'relaxation' by Alsop \& Marco (2011), and may form a significant local factor in fold modification.

\section{Summary}

A range of post-buckle processes may have contributed to the final geometry of the slump folds. Thickening of upright fold limbs to create Class 1A folds suggests that a component of post-buckle vertical 'flattening' has operated during the slump process, while thickening of synformal hinges relative to neighbouring antiforms is consistent with gravity-driven hydroplastic flow of sediment from crests to troughs (Fig. 10). Although buckle folds may have initiated during layer-parallel shortening associated with pure shear, they were subsequently modified by downslope-directed simple shear resulting in overturned Class 2 folds (Farrell \& Eaton 1987; Alsop \& Marco 2011, 2013) (Fig. 10). In addition, other more 
nebulous influences such as locally increasing fluid pressure during the folding process may lead to a relative weakening of competent layers (e.g. Price \& Cosgrove 1990, p.295), thereby encouraging more Class $1 \mathrm{C}$ and Class 2 similar folds to develop during the evolution of the slump. Overall volume loss via expulsion of fluids (e.g. Price \& Cosgrove 1990) and increased grain packing may also influence the geometry of folds, although is difficult to quantify. These processes may collectively modify the initial fold shape to create the range of fold geometries that are currently observed in the study area.

\section{Are estimates of viscosity contrasts in slumps folds similar to those in metamorphic rocks?}

Schmalholz \& Podladchikov (2001) have demonstrated via strain contour maps that viscosity contrasts between layers of between 50 and 250 are typical in metamorphic rocks (Schmalholz \& Podladchikov 2001; see also Hudleston \& Treagus 2010). These values are however observed to vary depending on lithological controls (e.g. Druguet et al. 2009, their fig. 3). Schmalholz \& Podladchikov (2001, p. 211) also note that the strain contour map is applicable not just to buckles created during pure shear, but also to asymmetric folds that formed during simple shear. In general, the values of viscosity contrast calculated from the slump folds in the study area display a similar range to that obtained from metamorphic rocks (Fig. 8, 9).

Thus, similar geometries between metamorphic folds created during HRD and slump folds formed during SSD are borne out by a similar range of viscosity contrasts on strain contour maps. However, folds within the case study slumps form before the overlying sedimentary cap was deposited out of suspension "in a matter of just hours or days" (Alsop et al. 2016, p.80) and absolute viscosities in slumps will therefore be much lower. As a guide, samples of modern Dead Sea sediment yield viscosity measurements of just 0.3 Pa.s and 3 $\mathrm{Pa} . \mathrm{s}$ at depths of $10 \mathrm{~cm}$ and $30 \mathrm{~cm}$ respectively below the present sediment surface (Wetzler et al. 2010, p.304), while Levi et al. (2008) suggest that detrital layers in the Lisan Fm. have dynamic viscosity values in the range of $0.03-0.3 \mathrm{~Pa}$.s. In terms of strain rates, Price \& Cosgrove (1990, p.369) estimated the time taken during HRD to create folds of $500 \mathrm{~m}$ wavelength, based on typical plate tectonic velocities of $\sim 3.3 \mathrm{~cm} /$ year, and suggested strain rates of $10^{-13} / \mathrm{s}$. If we make a crude assumption within the case study that a $1 \mathrm{~m}$ wavelength slump fold is formed in 1 day, (Alsop et al. 2016), then suggested strain rates during SSD are of the order of $10^{-5} / \mathrm{s}$, while a similar fold forming more slowly over 1 week gives strain rates of $10^{-6} / \mathrm{s}$. The conclusion is that, despite the geometrical similarity and similar range of viscosity contrasts between metamorphic folds and SSD folds, the strain rates within slumps that create MTDs are 7-8 orders of magnitude greater and may be viewed as geologically instantaneous.

There are a number of considerations when estimating viscosity contrasts and total shortening within beds defining slump folds. Price \& Cosgrove (1990, p.299) note that the amount of bulk layer-parallel shortening that develops before buckles start to amplify increases as the viscosity contrast decreases. This idea was developed further by Treagus (1997) who suggested that there may be between 5 - 20\% bulk (layer-parallel) shortening 
before buckles start to amplify, with this pre-buckle shortening most significant in modelled folds with lower viscosity ratios (Treagus 1997; Hudleston \& Treagus 2010, p.2059). Teixell \& Koyi (2003) and Koyi et al. (2004) also note that $20 \%$ layer-parallel shortening may develop in models undergoing folding and thrusting. The net result may be that Schmalholz \& Podladchikov (2001) strain plots underestimate total shortening as they fail to take account of this layer-parallel component.

It has also been suggested that for a regular fold wave-train with a dominant wavelength to develop, the viscosity-ratio should be >100:1, otherwise layer-parallel shortening (noted above) that pre-dates buckling becomes so large that it masks and would 'overshadow folding' (Biot 1957, see discussion in Price \& Cosgrove 1990, p. 281). However, our results suggest that in some cases, fold wave-trains may display viscosity ratios of significantly less than 100:1 (e.g. Fig. 8c), and in some instances less than50:1 (Fig. 8o). It has been recognised from experiments that with increased homogeneous layer-parallel shortening that accompanies the buckling, then wave-trains with dominant wavelengths may indeed form at significantly lower viscosity contrasts of 25:1 (Huddleston 1973). Our results are therefore consistent with a component of homogeneous layer shortening that accompanies the buckling of competent layers during the slump process. Further details of the role of viscosity ratios in the folding process are provided by Schmid et al. (2010) and more recently are reviewed by Schmalholz \& Mancktelow (2016).

The correlation we describe between fold wavelength $(\lambda)$ and amplitude $(A)$ (e.g. Fig. $9 \mathrm{a}-\mathrm{c}$ ) is in general agreement with Wetzler et al. (2010) who correlated $A^{2}$ and wavenumber (i.e. 1/ $\lambda$ ) in slump folds from the Lisan Fm. Wetzler et al. (2010) suggest that the observed folds form part of a continuum of structures that initiate as linear waves during KelvinHelmholtz instability and evolve in to folds, finally culminating in breccias associated with turbulence and instability (also see Alsop \& Marco 2011, p.453). Analysis of fold wavelength $(\lambda)$ to layer thickness $(\mathrm{h})$ from the measured slump folds (e.g. Fig. 8a) suggests a general ratio of $\sim 5: 1$ (Fig 9d,e,f). This is significantly less than the 27:1 ratio calculated by Twiss $\&$ Moore (2007, p.562) for folds in lithified rocks. Although this $\lambda / \mathrm{h}$ value is viewed as a constant, it is recognised that wavelength is not a very sensitive function, as slight changes result in significant differences to the estimate of the viscosity contrast. In addition, if there is a component of multilayer folding (i.e. layers are more closely spaced) then the wavelength produced will be less than for an equivalent thickness of a single layer buckle fold (Price \& Cosgrove 1990, p. 310). The net effect of this multilayer folding would be to increase both the $A / \lambda$ and $\mathrm{h} / \lambda$ values. This will result in an overestimate of the $\%$ contraction, and a potential over- or under estimate of the viscosity contrast on the Schmalholz \& Podladchikov (2001) strain maps designed for single layer folds. The role of multilayer spacing on the $\lambda$ to $\mathrm{h}$ ratios of individual folded layers have been recently summarised by Schmalholz \& Mancktelow (2016, p.1437).

It is interesting to note that buckle fold layers that are entirely isolated within aragonite-rich units may display greater viscosity contrast as \% contraction increases (e.g. Fig. 8a-c), whereas if layers are closer together, there is an apparent reduction in viscosity contrast with increasing \% contraction resulting in less steep trends on strain contour plots (Fig. 8f, i, 1, o). This apparent discrepancy may reflect a number of variables. If a measured single layer fold actually forms part of a multi-layer, the multilayer will act as a thicker 
mechanical unit, with a greater effective thickness, meaning that measured $\mathrm{h} / \lambda$ values would be under estimated. This multilayer influence may be most significant where folds initiate and amplitudes are lower (with lower \% contraction) and may result in some data sets defining less steep trends on strain plots i.e. the effect of multi-layers may be to overestimate viscosity contrasts at lower values of \% shortening (see also Druguet et al. 2009, p.503). An alternative interpretation would be that viscosity contrasts actually vary as folds develop due to expulsion of fluids during folding. Price \& Cosgrove (1990, p.398) examined folds formed during HRD and argued that "the fold acts as a pump which, if the external energy is sufficient, continues to extrude fluids from itself until it is almost dry". Any expulsion of fluids leading to variation in viscosity contrasts would have the greatest effect on resulting fold geometries if it occurred relatively early in the folding process when amplitudes are smaller and before fold wavelengths are established in the system. We here suggest that during SSD, a preferential expulsion of fluids from weaker (aragonite-rich) layers as the \% shortening increases, would lead to an increase in viscosity of these layers and consequently a reduction in the contrast between viscosities of the aragonite and detrital-rich layers.

In summary, the overall correlation between bed thickness (h), fold wavelength $(\lambda)$ and amplitude $(A)$ suggests that buckling is the dominant fold mechanism in the slump folds of the study area (Fig. 8, 9). Strain maps developed by Schmalholz \& Podladchikov (2001) are equally applicable to folds created during HRD of metamorphic rocks and slump folds formed during SSD, and suggest similar viscosity contrasts ranging from 50-250. Within slump folds, components of potential layer-parallel shortening would lead to an underestimate of total shortening, while an element of multi-layer folding may lead to an overestimate of the \% contraction and less accurate estimates of viscosity contrasts. We speculate that it may also be possible for viscosity contrasts to actually vary as fold trains evolve due to preferential expulsion of fluids as folds tighten.

\section{Conclusions}

In this study, classical techniques of structural analysis developed by John Ramsay amongst others during the investigation of folds formed in metamorphic terranes have been applied to folds generated within unlithified soft-sediments. Using superbly exposed slump folds created during SSD within MTDs of the Lisan Fm., we have demonstrated that recumbent fold packages define en echelon fold trains that display a harmonic style of folding. Slump folds are entirely systematic and should not be viewed as 'chaotic', although upright buckles may form disharmonic folds that cannot be traced for significant distances along their axial surfaces before truncation by overlying sedimentary caps. We also recognise a similar range of refold patterns created during SSD within slump folds when compared to HRD in metamorphic rocks. Refolds may also be truncated by the overlying sedimentary cap, indicating that they formed during a single progressive slump event and are not a product of superposition of later 'events' (Fig. 10).

A wide variety of fold styles ranging from Class 1A, 1B, 1C, Class 2 and Class 3 geometries are developed within slumps of the case study. Within individual folds, aragoniterich layers may display Class 2 (similar) folds, while adjacent detrital-rich beds are marked by Class $1 \mathrm{C}$ fold geometries. Such varying styles of folding allow individual folds to 
propagate further along their axial planes without encountering significant accommodation problems around the fold hinge. Upright buckle folds defined by detrital-rich marker beds display a Class 1B (parallel) style of folding, while recumbent folds display Class 2 (similar) fold styles. Upright fold hinges and axial planes may undergo rotation during progressive simple-shear dominated deformation as the MTD moves downslope under the influence of gravity. In detail, thickening of upright fold limbs relative to the hinge to form Class $1 \mathrm{C}$ folds suggests a component of vertical flattening that post-dates original folding, but pre-dates deposition of the overlying sedimentary cap shortly after slope failure. This flattening appears to be most significant towards the top of each MTD, where sediments are more watersaturated (Fig. 10). In addition, upright folds are also subsequently modified by flow of sediment from antiformal crests to troughs of synforms, together with simple shear deformation associated with continued downslope movement that results in Class $1 \mathrm{C}$ and Class 2 similar folds displaying recumbent attitudes (Fig. 10).

Our study has involved the measurement of fold wavelength $(\lambda)$, amplitude $(A)$ and bed thickness $(\mathrm{h})$ in order to estimate $\%$ shortening and viscosity contrast between folded layers on strain contour maps (Schmalholz and Podladchikov, 2001). Estimates of viscosity contrast from folded layers within metamorphic rocks formed during HRD and slump folds created during SSD both suggest broadly similar values in the range of 50-250. We speculate that it may also be possible for viscosity contrasts to vary as fold trains evolve due to preferential expulsion of fluids as folds tighten. The geologically instantaneous nature of slope failure, which may be 7-8 orders of magnitude greater than folding associated with HRD, indicates that the absolute viscosities will however be considerably lower in slumps.

\section{Acknowledgements}

RW was supported by the Israel Science Foundation (ISF grant No. 868/17). SM acknowledges the Israel Science Foundation (ISF grant No. 1436/14) and the Ministry of National Infrastructures, Energy and Water Resources (grant \#214-17-027). TL acknowledges the Israeli government GSI DS project 40706. We thank Stefan Schmalholz and Tim Dooley for careful and constructive reviews, together with Hermann Lebit for efficient editorial handling. Finally, GIA would like to take this opportunity to acknowledge John Ramsay's support while a post-doc at ETH Zurich in the 1980's.

\section{Figure Captions}

Fig 1. a) Tectonic plates in the Middle East. General tectonic map showing the location of the present Dead Sea Fault (DSF). The Dead Sea Fault transfers the opening motion in the Red Sea to the Taurus-Zagros collision zone. b) Generalised map (based on Sneh and Weinberger 2014) showing the current Dead Sea including the position of the Masada, Peratzim and Zin localities referred to in the text. The extent of the Lisan Fm. outcrops are also shown, together with the general slump directions of the MTD's around the basin. 
Fig 2 a, b) Photographs of light-coloured aragonite-rich laminae and dark detrital-rich laminae forming the Lisan Fm. An infilling sedimentary cap that blankets underlying structures at Zin is shown in a), while b) is a close-up image of undeformed laminae from Peratzim. Refer to Fig. 1b for details of locations. Pairs of photographs (c, e, g) and associated stereonets $(\mathrm{d}, \mathrm{f}, \mathrm{h})$ of NE-verging fold and thrusts developed within slump 4 at Peratzim (see Alsop et al. 2016). In stereonets, fold hinges (solid red circles), poles to axial planes (open blue squares), and associated thrusts are shown as red great circles and poles as solid red squares. Calculated slump transport is towards the NE (see Alsop \& Marco 2012a). All photographs marginally overlap with one another and have NE on the right-hand side for consistency.

Fig. 3 Harmonic and disharmonic fold analysis from folds in Masada (see Fig. 1b for location). a) Recumbent en echelon folds verging towards the East. The half wavelength of folds is approximated by the spacing (S) of adjacent axial surfaces (shown in red and blue), while the continuity of the axial surface may be directly measured $(\mathrm{D})$, to produce a ratio $(\mathrm{H})$ which is equivalent to D/S (see Twiss \& Moores 2007, p.290). b) Stereonet of folds from Masada shown in a) with transport direction towards $074^{\circ}$ and key to stereonets given below. c) Graph showing D plotted against S. d) Graph showing H plotted against S. e) Photograph of individual Masada locality with stereonet $\mathrm{f}$ ), and plots of H, D and S parameters (g, h). i) Photograph of individual Masada locality with stereonet $\mathrm{j}$ ), and plots of parameters $(\mathrm{k}, \mathrm{l})$. In all stereonets, fold hinges (solid red circles), mean fold hinge (open red circle), poles to axial planes (solid blue squares), mean axial plane (blue great circle and pole as open blue circle). Great circle and pole to sub-horizontal bedding are shown in green in $\mathrm{f}, \mathrm{j}$ ).

Fig. 4 Photogaphs (a-d) of minor folds within Moine psammites from the classic locality by Loch Monar Dam in NW Scotland [UK Grid NH1989 3882] used by Ramsay $(1962,1967)$ to establish a refold classification scheme. a) Plan view of intense minor folding within interlayerered pelites and psammites. Adjacent axial traces (highlighted in blue and red) define harmonic folds. b, c) Plan view of Type 1 dome and basin fold interference patterns with bedding in psammite (highlighted in yellow) defining closed outcrop patterns. d) Plan view of Type 3 hook fold interference patterns with axial traces of older folds (highlighted in red) being refolded by younger folds (highlighted in blue). Photographs (e-j) of sections through refolds within slumps at Peratzim (See Fig. $1 \mathrm{~b}$ for location). e, f) Type 1 dome and basin refold pattern, with coloured pencils parallel to the fold hinges in e). g) Type 2 'mushroom' refold pattern. h, i, j) Type 3 hook interference patterns. In j), the refold is truncated by an overlying erosive surface and sedimentary cap. $10 \mathrm{~cm}$ long chequered rule and $15 \mathrm{~mm}$ diameter coin for scale.

Fig 5 a) Dip isogons join points of equal dip on adjacent folded surfaces, $t_{0}$ is layer thickness measured along the axial surface, while $t_{\alpha}$ is orthogonal layer thickness measured at various angles $(\alpha)$ to the reference plane. b) Class 1 folds are marked by convergent dip isogons, c) Class 2 folds by parallel dip isogons, and d) Class 3 folds by diverging dip isogons. e) Singlelayer train of buckle folds defined by a detrital-rich bed at Peratzim (see Fig. 1b for location). Buckle folds display a progressive tightening coupled with a rotation and reduction in dip of the axial surfaces towards the downslope direction. f) Excavation of buckle folds shown in e) reveals 3D variation in fold hinge orientations marked by different coloured pencils. $10 \mathrm{~cm}$ 
chequered rule for scale. g) Stereonet of upright folds (in red) and more overturned folds with inverted lower limbs (in blue) shown in e) and f). Axial planes are shown as great circles, and poles as solid squares. Fold hinges are shown by solid circles. h) Close-up photograph of buckle folds that display thickened overturned limbs relative to the upper limbs (see Fig. 5e for position). Representative $70^{\circ}$ and $45^{\circ}$ dip isogons are drawn on the upper and lower limbs of the fold. i) $\mathrm{t}_{\alpha}{ }_{\alpha}$ graph (where $\mathrm{t}^{\prime}{ }_{\alpha}=\mathrm{t}_{\alpha} / \mathrm{t}_{0}$ ) plotted against dip angle $(\alpha)$ to create a series of fold classes (Ramsay 1967, p. 366). t' alpha graph relates to dip-isogon analysis of detritalrich (blue) and aragonite-rich (red) layers around buckle fold shown in h). Data is divided into upper fold limbs (squares) and lower fold limbs (circles).

Fig. 6 Paired photographs and t' alpha $(\alpha)$ plots relating to dip-isogon analysis of different layers around folds (a-b, c-d, e-f, g-h). Dip isogons join points of equal dip on adjacent folded surfaces, $t_{0}$ is layer thickness measured along the axial surface, while $t_{\alpha}$ is orthogonal layer thickness measured at various angles ( $\alpha$ ) to the reference plane (see Fig. 5a). Upper fold limbs are represented by coloured circles and lower limbs by squares. Photographs a) and c) are from Peratzim, while e) and g) are from Zin.

Fig. 7 Analysis of post-buckle flattening in folds developed directly beneath sedimentary caps. In each case, paired photographs and associated inverse layer thickness analysis based on Lisle (1992) are shown in a-b) from Peratzim, e-f) from Masada and i-j) from Peratzim. a) and $b$ ) illustrate the inverse thickness method, which plots $(1 / t)$ for various orientations of the layer tangent around the fold, where $t$ is the orthogonal thickness between tangents for the inner and outer layer boundaries (see Lisle 1992, p.370). The inverse thickness (1/t) is plotted from a common central point, each in the direction of the tangent to create an array of points to which a best-fit ellipse is matched. Examples of upslope (SW in red) tangents drawn at $70^{\circ}$, and downslope (NE in blue) tangents drawn at $45^{\circ}$ are shown in a) and b). Photographs and ellipses are 'unstrained' back to circles using the method of Srivastava and Shah (2006), and are shown in the right-hand side in c-d), g-h) and k-l). In each case, data collected from the western or SW (upslope) limb is shown in red, while the eastern or NE (downslope) limb is shown in blue. The change in area from ellipse to restored circle does not represent a change in volume of the sediment.

Fig. 8 Photographs, associated graphs showing wavelength plotted against amplitude / wavelength, and strain contour maps of Schmalholz \& Podladchikov (2001) for a series of individual fold trains (a-c, d-f, g-i, j-l, m-o, p-r). In e) and f), blue squares represent data collected from the same bed in an adjacent outcrop of the slump. In a), wavelength $(\lambda)$ is defined as the distance between two points that occupy a similar position on the fold train (i.e. between adjacent synform hinges). Thickness of a layer (h) is measured orthogonal to the folded bed, while amplitude $(A)$ is defined as half the distance from the trough to the crest of upright folds. Strain contour plots of Schmalholz \& Podladchikov (2001) show estimated \% shortening and viscosity contrasts for folded layers. In each of the graphs, different coloured symbols represent different individual fold trains. Arrows show general trends of data on each graph, while circled letters correspond to individual folds marked on adjacent photographs. Yellow notebook (21 cm long), $10 \mathrm{~cm}$ chequered rule, and $15 \mathrm{~mm}$ diameter coin act as scales on photographs,

Fig. 9 a-c) Graphs showing fold amplitude plotted against fold wavelength for a) minor folds ( $<200 \mathrm{~mm}$ wavelength), b) mesoscopic folds ( $<1000 \mathrm{~mm}$ wavelength) and c) overall data on a log-log plot. d-f) Graphs showing folded layer thickness against fold wavelength for d) 
minor folds ( $<200 \mathrm{~mm}$ wavelength), e) mesoscopic folds ( $<1000 \mathrm{~mm}$ wavelength) and $\mathrm{f}$ ) overall data on a log-log plot. g-h) Graphs showing folded layer thickness against fold amplitude for g) minor folds ( $<100 \mathrm{~mm}$ amplitude), b) mesoscopic folds ( $<500 \mathrm{~mm}$ amplitude). i) Strain contour map of Schmalholz \& Podladchikov (2001) showing estimated $\%$ shortening and viscosity contrasts for folded layers. In each of the graphs (a-i), different coloured symbols represent different individual fold trains, including those shown in Figure 8.

Fig. 10 Schematic summary cartoon highlighting the main geometries and styles of folding observed during soft-sediment deformation of competent (brown) markers above a basal detachment. Layer-parallel shortening associated with pure shear creates upright Class 1B buckles (left of diagram) that undergo vertical flattening (large blue arrow) and flow of sediment down fold limbs towards synformal troughs to create Class 1A antiforms. A potential component of density-driven flow up into antiforms may be associated with Rayleigh-Taylor instabilities. Increasing downslope-directed simple shear deformation towards the right of the figure results in rotation of antiformal and synformal axial surfaces (red and blue dashed lines respectively) towards the flow plane, resulting in overturned and harmonic folds with Class 1C or Class 2 (similar) geometry. Refolded folds created during the progressive downslope-directed shearing are truncated by the overlying erosive sedimentary cap (orange bed) that is deposited from suspension following slope failure.

\section{References}

Alsop, G.I., Bryson, R., Hutton, D.H.W. 1998. Ductile transpression and localization of deformation along tectonic boundaries in the Caledonides of northwestern Ireland. Geological Magazine 135, 699718.

Alsop, G.I., Holdsworth, R.E. 1993. The distribution, geometry and kinematic significance of Caledonian buckle folds in the western Moine Nappe, northwestern Scotland. Geological Magazine 130, 353-362.

Alsop, G.I., Holdsworth, R.E., McCaffrey, K.J.W. 2007. Scale invariant sheath folds in salt, sediments and shear zones. Journal of Structural Geology 29, 1585-1604.

Alsop, G.I., Marco, S 2011. Soft-sediment deformation within seismogenic slumps of the Dead Sea Basin. Journal of Structural Geology 33, 433-457.

Alsop, G.I., Marco, S. 2012a. A large-scale radial pattern of seismogenic slumping towards the Dead Sea Basin. Journal of the Geological Society 169, 99-110.

Alsop, G.I., Marco, S. 2012b. Tsunami and seiche-triggered deformation within offshore sediments. Sedimentary Geology 261, 90-107.

Alsop, G.I., Marco, S. 2013. Seismogenic slump folds formed by gravity-driven tectonics down a negligible subaqueous slope. Tectonophysics 605, 48-69.

Alsop, G.I., Marco, S. 2014. Fold and fabric relationships in temporally and spatially evolving slump systems: A multi-cell flow model. Journal of Structural Geology, 63, 27-49.

Alsop, G.I., Marco, S., Weinberger, R., Levi, T. 2016. Sedimentary and structural controls on seismogenic slumping within Mass Transport Deposits from the Dead Sea Basin. Sedimentary Geology 344, 71-90.

Alsop, G.I., Marco, S., Levi, T., Weinberger, R. 2017a. Fold and thrust systems in Mass Transport Deposits. Journal of Structural Geology 94, 98-115. 
Alsop, G.I., Marco, S., Weinberger, R., Levi, T. 2017b. Upslope-verging back thrusts developed during downslope-directed slumping of mass transport deposits. Journal of Structural Geology 100, 45-61.

Alsop, G.I., Weinberger, R., Marco, S. 2018. Distinguishing thrust sequences in gravity-driven fold and thrust belts. Journal of Structural Geology 109, 99-119.

Alsop, G.I., Weinberger, R., Marco, S., Levi, T. 2019a. Identifying soft-sediment deformation in rocks. Journal of Structural Geology, doi: 10.1016/j.jsg.2017.09.001

Alsop, G.I., Weinberger, R., Marco, S., Levi, T. 2019b. Fold and thrust systems in mass transport deposits around the Dead Sea Basin. In: Ogata, K., Festa, A., Pini, G.A. (Editors). Submarine landslides: subaqueous mass transport deposits from outcrops to seismic profiles. American Geophysical Union Monograph Series. Wiley. (in press).

Bartov, Y., Steinitz, G., Eyal, M., Eyal, Y., 1980. Sinistral movement along the Gulf of Aqaba - its age and relation to the opening of the Red Sea: Nature 285, 220-221.

Bartov, Y., Goldstein, S.L., Stein, M., Enzel, Y. 2003. Catastrophic arid episodes in the Eastern Mediterranean linked with the North Atlantic Heinrich events. Geology 31, 439-442.

Begin, Z.B., Ehrlich, A., Nathan, Y., 1974, Lake Lisan, the Pleistocene precursor of the Dead Sea: Geological Survey of Israel Bulletin, 63, p. 30.

Begin, B.Z., Steinberg, D.M., Ichinose, G.A., and Marco, S., 2005. A 40,000 years unchanging of the seismic regime in the Dead Sea rift: Geology, v. 33, p. 257-260.

Biot, M.A. 1957. Folding instability of a layered visco-elastic medium under compression. Proceedings of the Royal Society of London A242, 444-454.

Coward, M.P., Potts, G.J. 1983. Complex strain patterns developed at the frontal and lateral tips to shear zones and thrust zones. Journal of Structural Geology 5, 383-399.

Dasgupta, P. 2008. Experimental decipherment of the soft-sediment deformation observed in the upper part of the Talchir Formation (Lower Permian), Jharia Basin, India. Sedimentary Geology 205, 100110.

Druguet, E., Alsop, G.I., Carreras, J. 2009. Coeval brittle and ductile structures associated with extreme deformation partitioning in a multilayer sequence. Journal of Structural Geology 31, 498-511.

El-Isa, Z.H., Mustafa, H. 1986. Earthquake deformations in the Lisan deposits and seismotectonic implications. Geophysical Journal of the Royal Astronomical Society 86, 413-424.

Elliot, C.G., Williams, P.F. 1988. Sediment slump structures: a review of diagnostic criteria and application to an example from Newfoundland. Journal of Structural Geology 10, 171-182.

Farrell, S.G., Eaton, S. 1987. Slump strain in the Tertiary of Cyprus and the Spanish Pyrenees. Definition of palaeoslopes and models of soft sediment deformation. In: Deformation of Sediments and Sedimentary Rocks (edited by Jones, M.F. \& Preston, R.M.F.). Special Publication of the Geological Society of London 29, 181-196.

Fossen, H. 2016. Structural Geology. $2^{\text {nd }}$ Edition. Cambridge University Press, Cambridge, UK, p.510. Fossen, H., Cavalcante, G.C.G., Pinheiro, R.V.I., Archanjo, C.J. 2019. Deformation - Progressive or multiphase? Journal of Structural Geology doi: 10.1016/j.jsg.2018.05.006

Garfunkel, Z., 1981. Internal structure of the Dead Sea leaky transform (rift) in relation to plate kinematics: Tectonophysics 80, p. 81-108.

Haase-Schramm, A., Goldstein, S.L., Stein, M. 2004. U-Th dating of Lake Lisan aragonite (late Pleistocene Dead Sea) and implications for glacial East Mediterranean climate change. Geochimica et Cosmochimica Acta 68, 985-1005.

Haliva-Cohen, A., Stein, M., Goldstein, S.L., Sandler, A., Starinsky, A. 2012. Sources and transport routes of fine detritus material to the Late Quaternary Dead Sea Basin. Quaternary Science Reviews $50,55-70$. 
Hibbard, J., Karig, D.E. 1987. Sheath-like folds and progressive fold deformation in Tertiary sedimentary rocks of the Shimanto accretionary complex, Japan. Journal of Structural Geology 9, 845857.

Holdsworth, R.E., 1990. Progressive deformation structures associated with ductile thrusts in the Moine Nappe, Sutherland, N. Scotland. Journal of Structural Geology 12, 443-452.

Huddleston, P.J. 1973. An analysis of 'single layer' folds developed experimentally in viscous media. Tectonophysics 16, 189-214.

Huddleston, P.J. 1986. Extracting information from folds in rocks. Journal of Geological Education 34, 237-245.

Huddleston, P.J., Treagus, S.H. 2010. Information from folds: A review. Journal of Structural Geology 32, 2042-2071.

Ken-Tor, R., Agnon, A., Enzel, Y., Marco, S., Negendank, J.F.W., and Stein, M., 2001. Highresolution geological record of historic earthquakes in the Dead Sea basin: J. Geophys. Res., v. 106, p. 2221-2234.

Knipe, R.J. 1986. Deformation mechanism path diagrams for sediments undergoing lithification. Memoir of the Geological Society of America 166, 151-160.

Koyi, H.A., Sans, M., Teixell, A., Cotton, J., Zeyen, H. 2004. The significance of penetrative strain in the restoration of shortened layers - insights from sand models and the Spanish Pyrenees. In: McClay, K.R. (Editor) Thrust Tectonics and hydrocarbon systems. American Association of Petroleum Geology Memoir 82, 207-222.

Levi, T., Weinberger, R., Eyal, Y., Lyakhovsky, V., Heifetz, E. 2008. Velocities and driving pressures of clay-rich sediments injected into clastic dykes during earthquakes. Geophysical Journal International 175, 1095-1107.

Lisle, R.J. 1992. Strain estimation from flattened buckle folds. Journal of Structural Geology 14, 369371.

Lu, Y., Waldmann, N., Alsop, G.I., Marco, S. 2017. Interpreting soft sediment deformation and mass transport deposits as seismites in the Dead Sea depocentre. Journal of Geophysical Research: Solid Earth, 122. 10, 8305-8325.

Maltman, A. 1994. Deformation structures preserved in rocks. In: Maltman, A. (Editor) The Geological Deformation of Sediments. Chapman \& Hall, London. pp. 261-307.

Marco, S., Stein, M., Agnon, A., and Ron, H., 1996. Long term earthquake clustering: a 50,000 year paleoseismic record in the Dead Sea Graben: J. Geophys. Res., 101, 6179-6192.

Marco, S., Hartal, M., Hazan, N., Lev, L., Stein, M. 2003. Archaeology, history, and geology of the A.D. 749 earthquake, Dead Sea transform. Geology 31, 665-668.

Migowski, C., Agnon, A., Bookman, R., Negendank, J.F.W., and Stein, M., 2004, Recurrence pattern of Holocene earthquakes along the Dead Sea transform revealed by varve-counting and radiocarbon dating of lacustrine sediments: Earth and Planetary Science Letters, v. 222, p. 301-314.

Ortner, H., 2007. Styles of soft-sediment deformation on top of a growing fold system in the Gosau Group at Muttekopf, Northern Calcareous Alps, Austria: Slumping versus tectonic deformation, Sedimentary Geology, 196, 99-118.

Ortner, H., Kilian, S. 2016. Sediment creep on slopes in pelagic limestones: Upper Jurassic of Northern Calcareous Alps, Austria. Sedimentary Geology 344, 350-363.

Price, N.J., Cosgrove, J.W. 1990. Analysis of Geological Structures. Cambridge University Press. 502pp.

Ramsay, J.G. 1962. Interference patterns produced by the superposition of folds of 'similar' type. Journal of Geology 60, 466-481.

Ramsay, J.G. 1967. Folding and Fracturing of Rocks. McGraw-Hill, New York. 568pp. 
931

932

933

934

935

936

937

938

939

940

941

942

943

944

945

946

947

948

949

950

951

952

953

954

955

956

957

958

959

960

961

962

963

964

965

966

967

968

969

970

971

Ramsay, J.G. 1974. Development of chevron folds. Geological Society of America Bulletin 85, 17411754.

Ramsay, J.G., Huber M.I. 1987. The techniques of modern structural geology. Volume 2: Folds and Fractures. Academic Press London. 309-700p.

Schmalholz, S.M., Mancktelow, N.S. 2016. Folding and necking across the scales: a review of theoretical and experimental results and their applications. Solid Earth 7, 1417-1465.

Schmalholz, S.M., Podladchikov, Y.Y. 2001. Strain and competence contrast estimation from fold shape. Tectonophysics 340, 195-213.

Schmalholz, S.M., Schmid, D.W. 2012. Folding in power-law viscous multi-layers. Philosophical Transactions of The Royal Society, A. 370, 1798-1826.

Schmid, D.W., Schmalholz, S.M., Mancktelow, N.S., Fletcher, R.C. 2010. Comment on "Folding with thermal-mechanical feedback" Journal of Structural Geology 32, 127-130.

Sneh, A., Weinberger, R. 2014. Major structures of Israel and Environs, Scale 1:50,000. Israel Geological Survey, Jerusalem.

Srivastava, D.C., Shah, J. 2006. A rapid method for strain estimation from flattened parallel folds. Journal of Structural Geology 28, 1-8.

Teixell, A., Koyi, H.A. 2003. Experimental and field study of the effects of lithological contrasts on thrust-related deformation. Tectonics 22, 1054. Doi: 10.1029/2002TC001407

Tobisch, O.T. 1984. Development of foliation and fold interference patterns produced by sedimentary processes. Geology 12, 441-444.

Treagus, S. 1997. Modelling deformation partitioning in folds. In: Sengupta, S. (Editor), Evolution of geological structures in micro to macro-scales. Chapman and Hall, London. p.341-372.

Twiss, R.J., Moores, E.M. 2007. Structural geology. $2^{\text {nd }}$ edition. W.H. Freeman and Company. New York. 736pp.

Van der Pluijm, B.A., Marshak, S. 2004. Earth Structure. An introduction to structural geology and tectonics. $2^{\text {nd }}$ Edition. W.W. Norton and Company. New York. 656pp.

Waldron, J.W.F., Gagnon, J-F. 2011. Recognizing soft-sediment structures in deformed rocks of orogens. Journal of Structural Geology 33, 271-279.

Weinberger, R., Levi, T., Alsop. G.I., Eyal, Y. 2016. Coseismic horizontal slip revealed by sheared clastic dikes in the Dead Sea basin. Geological Society of America Bulletin 128, 1193-1206.

Weinberger, R., Levi, T., Alsop. G.I., Marco, S. 2017. Kinematics of Mass Transport |Deposits revealed by magnetic fabrics. Geophysical Research Letters 44, 7743-7749.

Wetzler, N., Marco, S., Heifetz, E. 2010. Quantitative analysis of seismogenic shear-induced turbulence in lake sediments. Geology 38, 303-306.

Woodcock, N. H 1976a. Ludlow Series slumps and turbidites and the form of the Montgomery Trough, Powys, Wales. Proceedings of the Geologists Association 87, 169-182.

Woodcock, N. H 1976b. Structural style in slump sheets: Ludlow Series, Powys, Wales. Journal of the Geological Society, London 132, 399-415.

Woodcock, N.H. 1979. The use of slump structures as palaeoslope orientation estimators.

Sedimentology, 26, 83-99. 


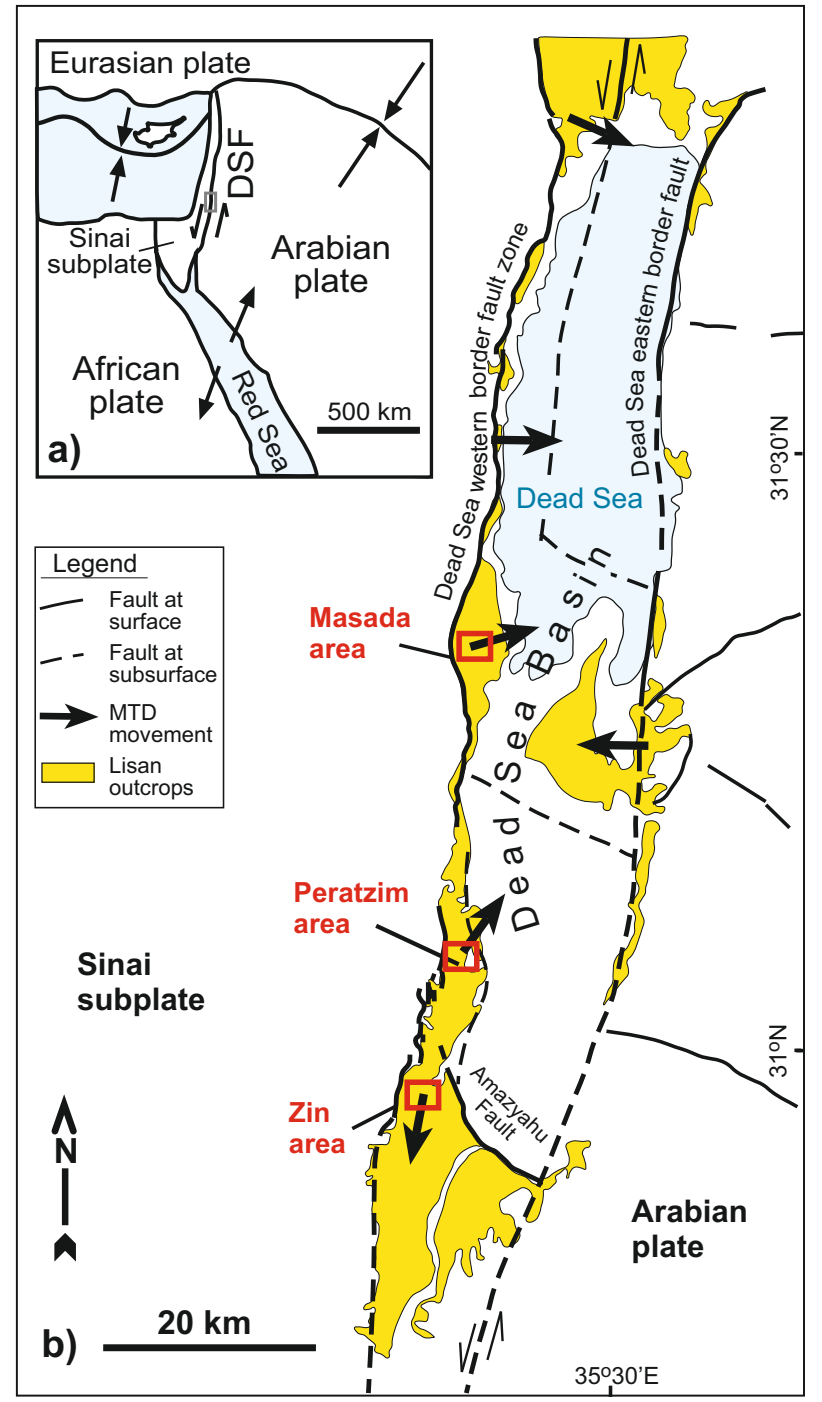



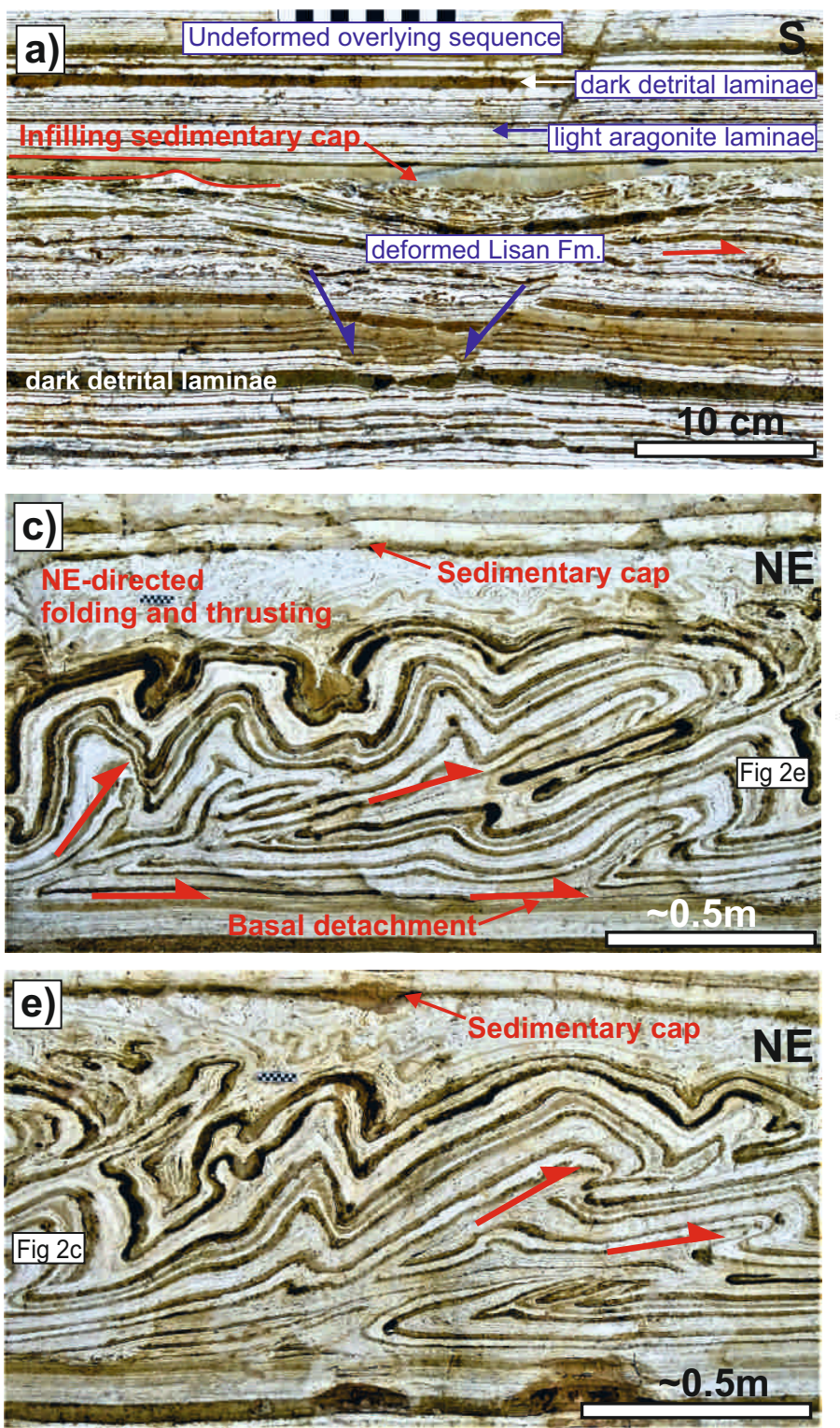

g) Sedimentary cap - NE

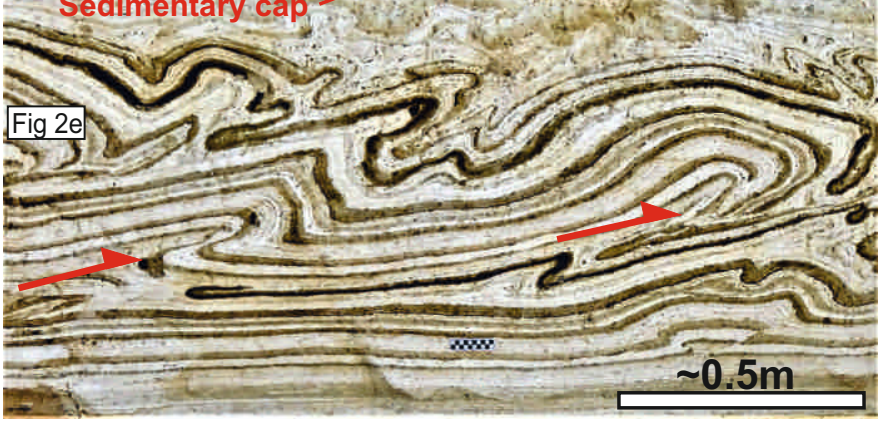

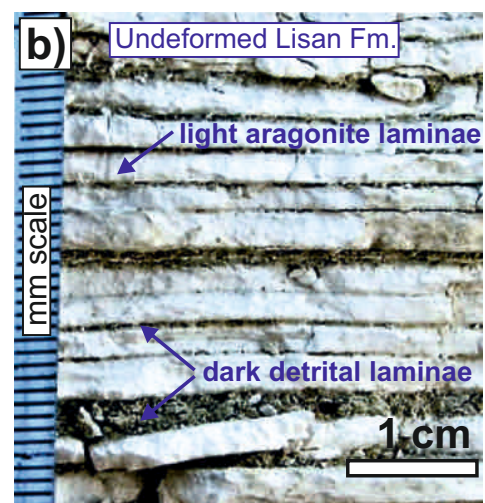
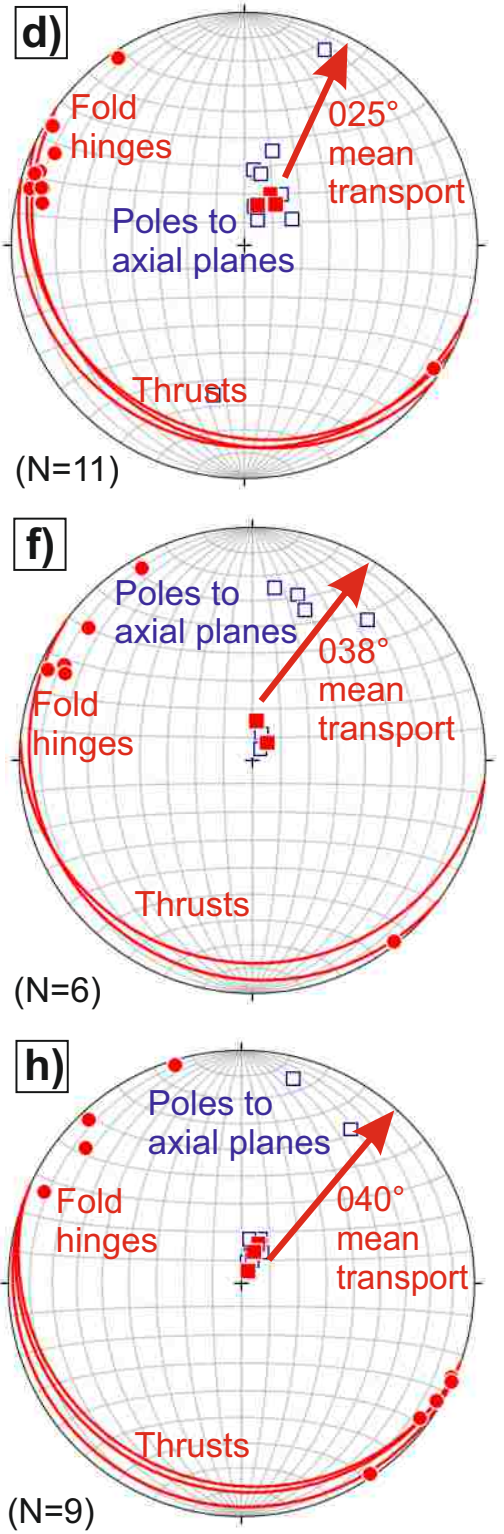

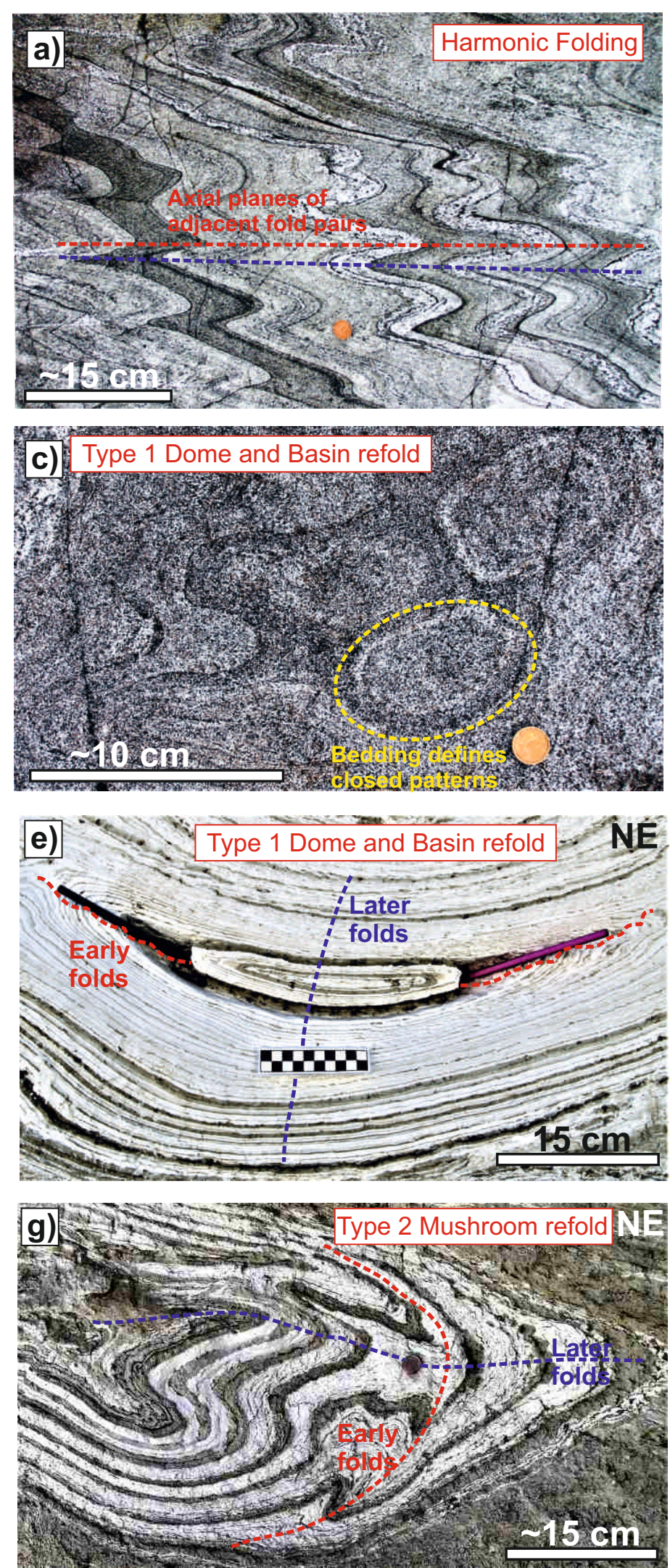

i) 139 6. Type 3 Hook refold 1 MEs

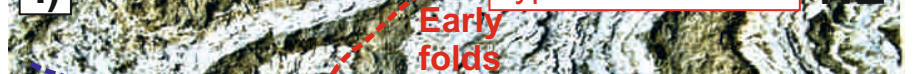
1.7.

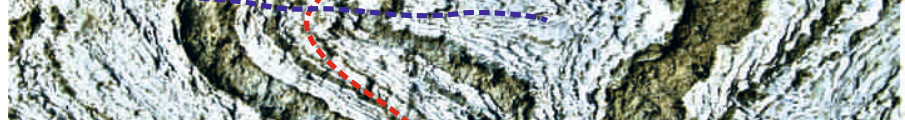

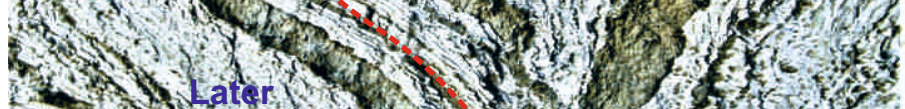

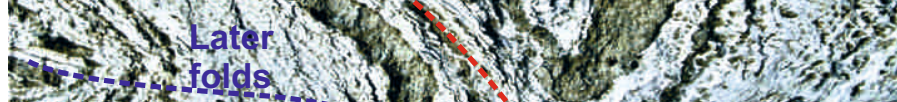

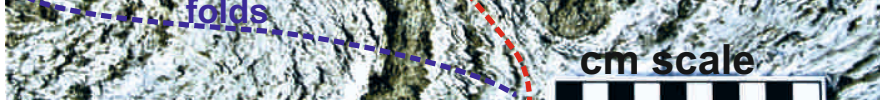

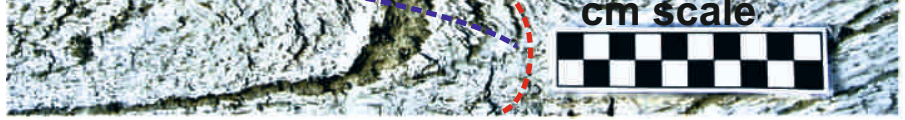
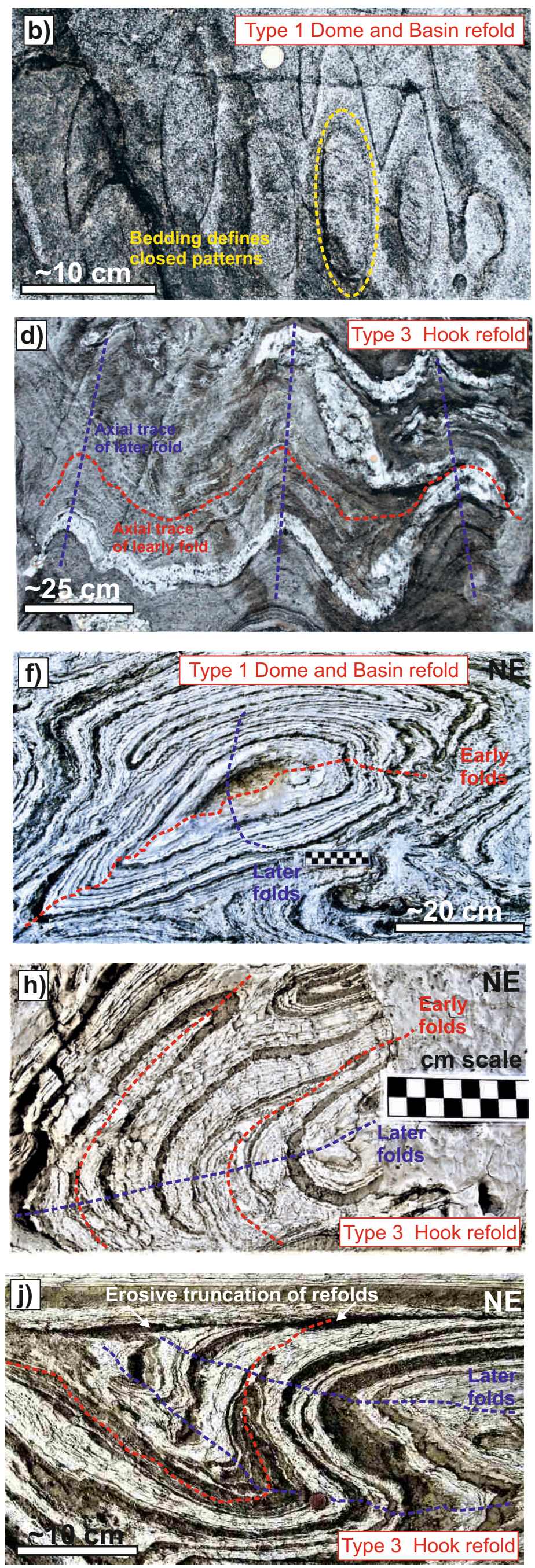


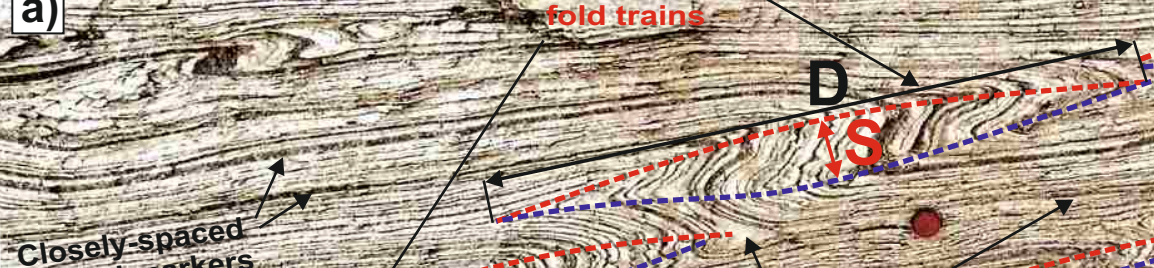

detrital makers

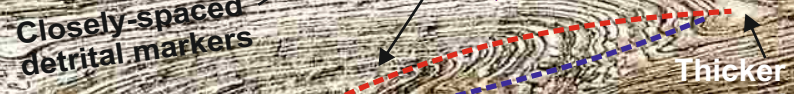

Hent

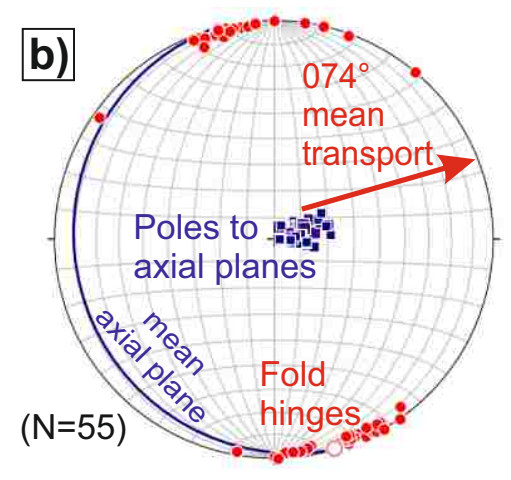

c)

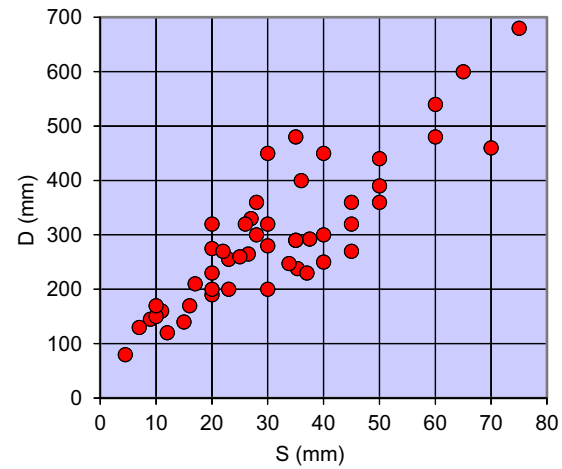

d)

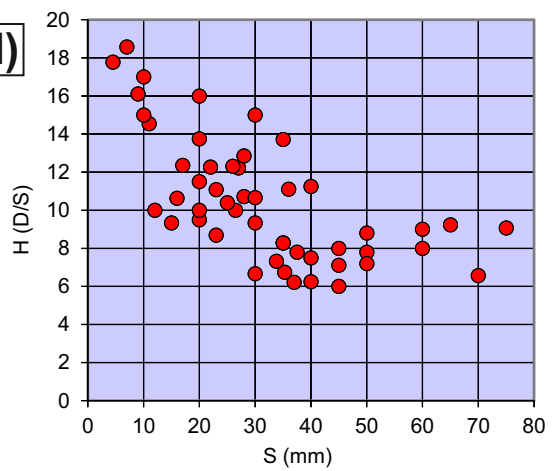

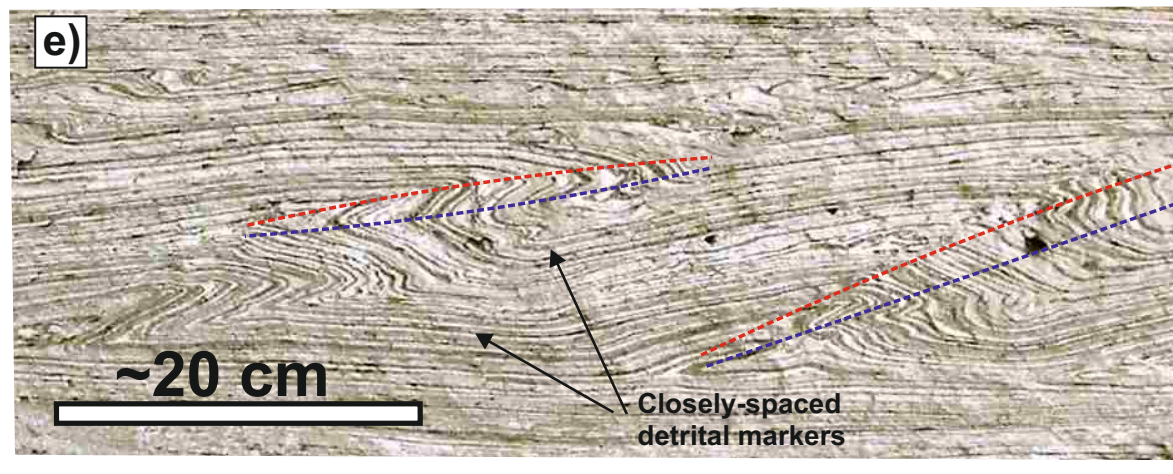

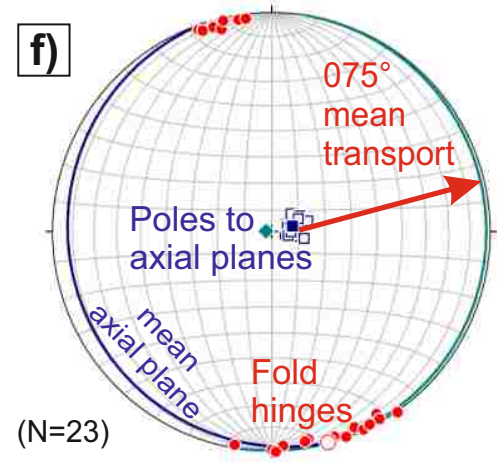

g)

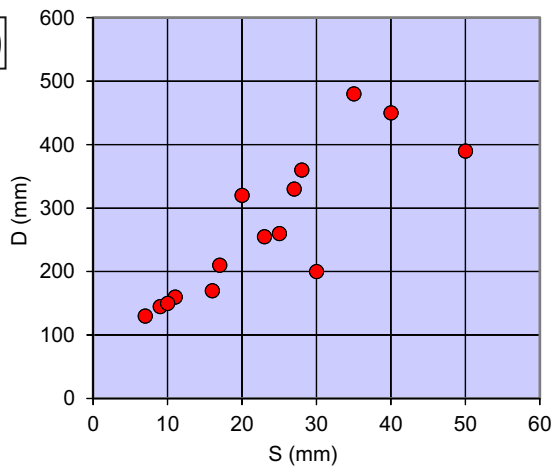

and E-

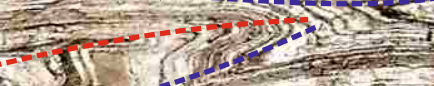
act--nt-

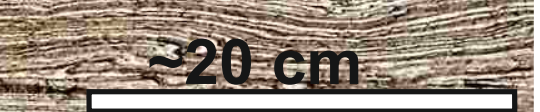
1. - 32 ath 3. ‥

\section{.}


b) Class 1 Folds - Convergent isogons
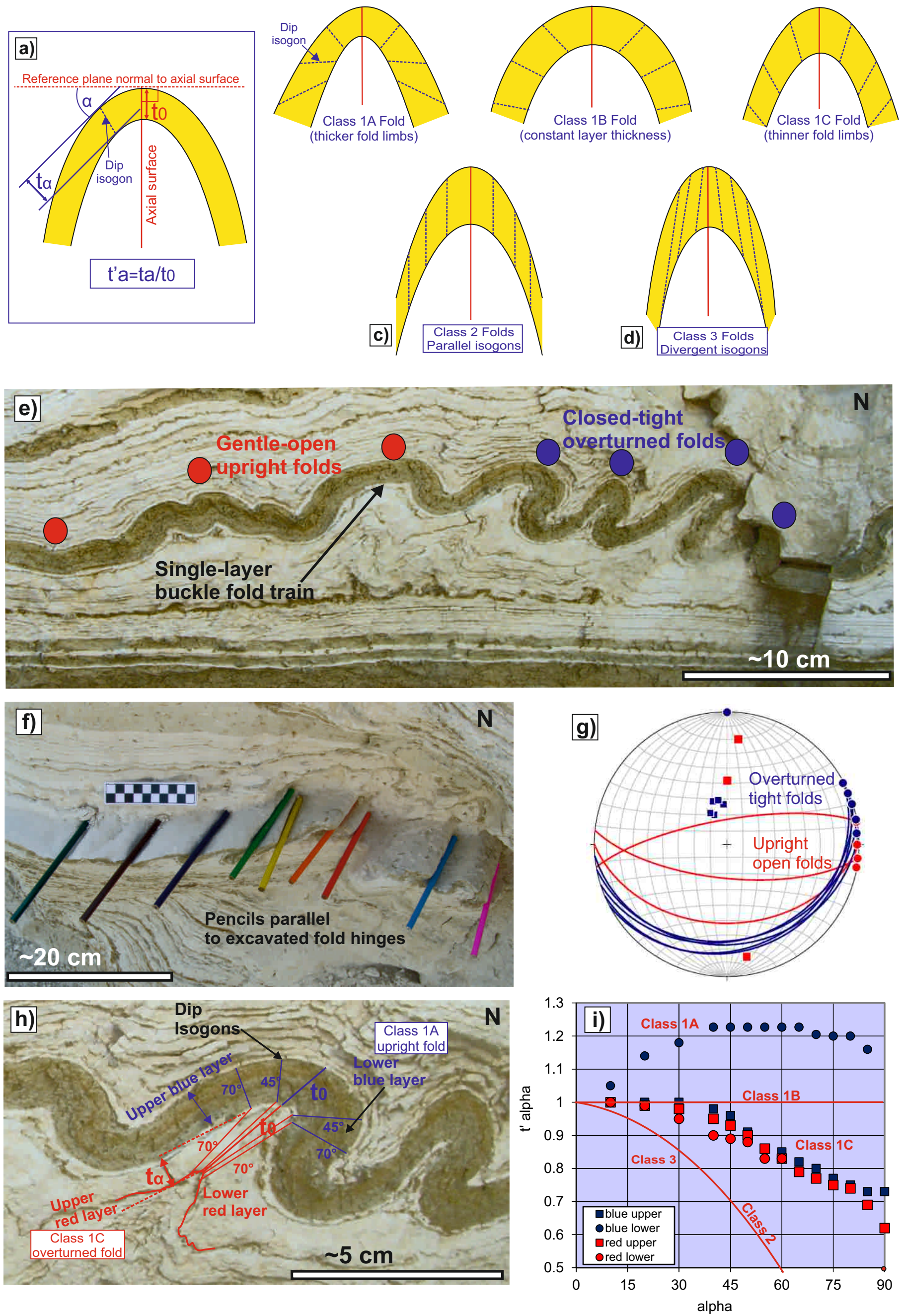

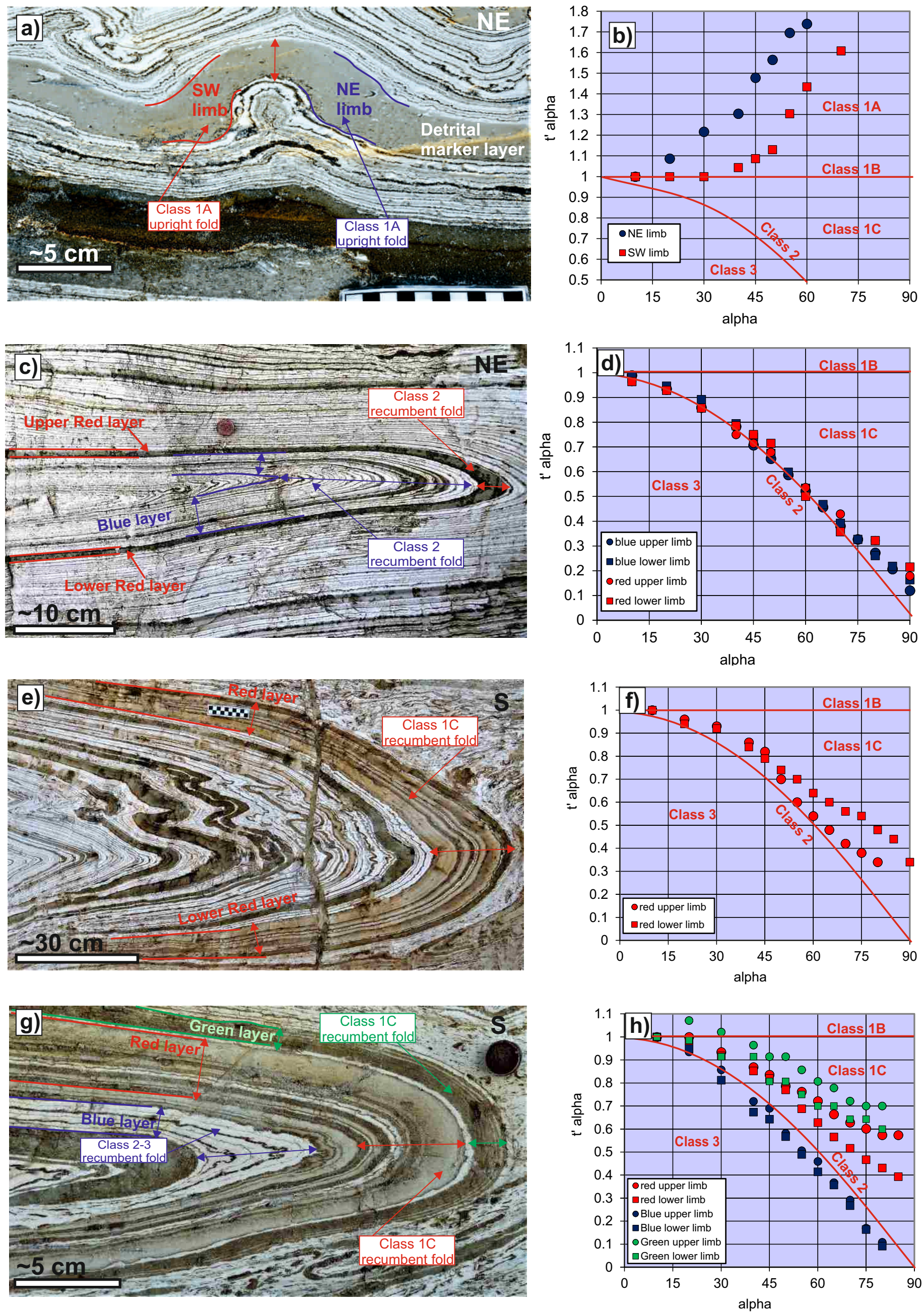

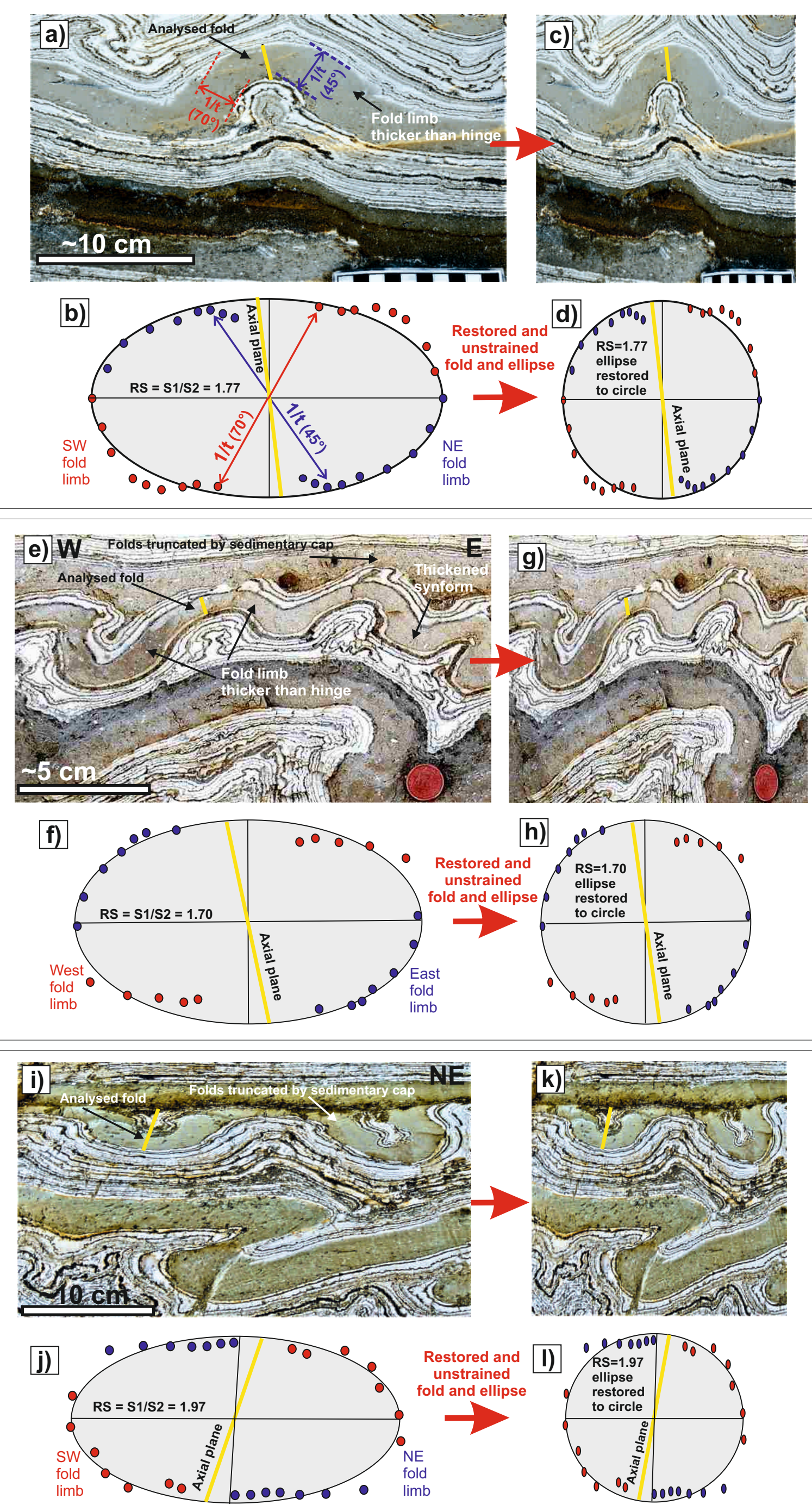

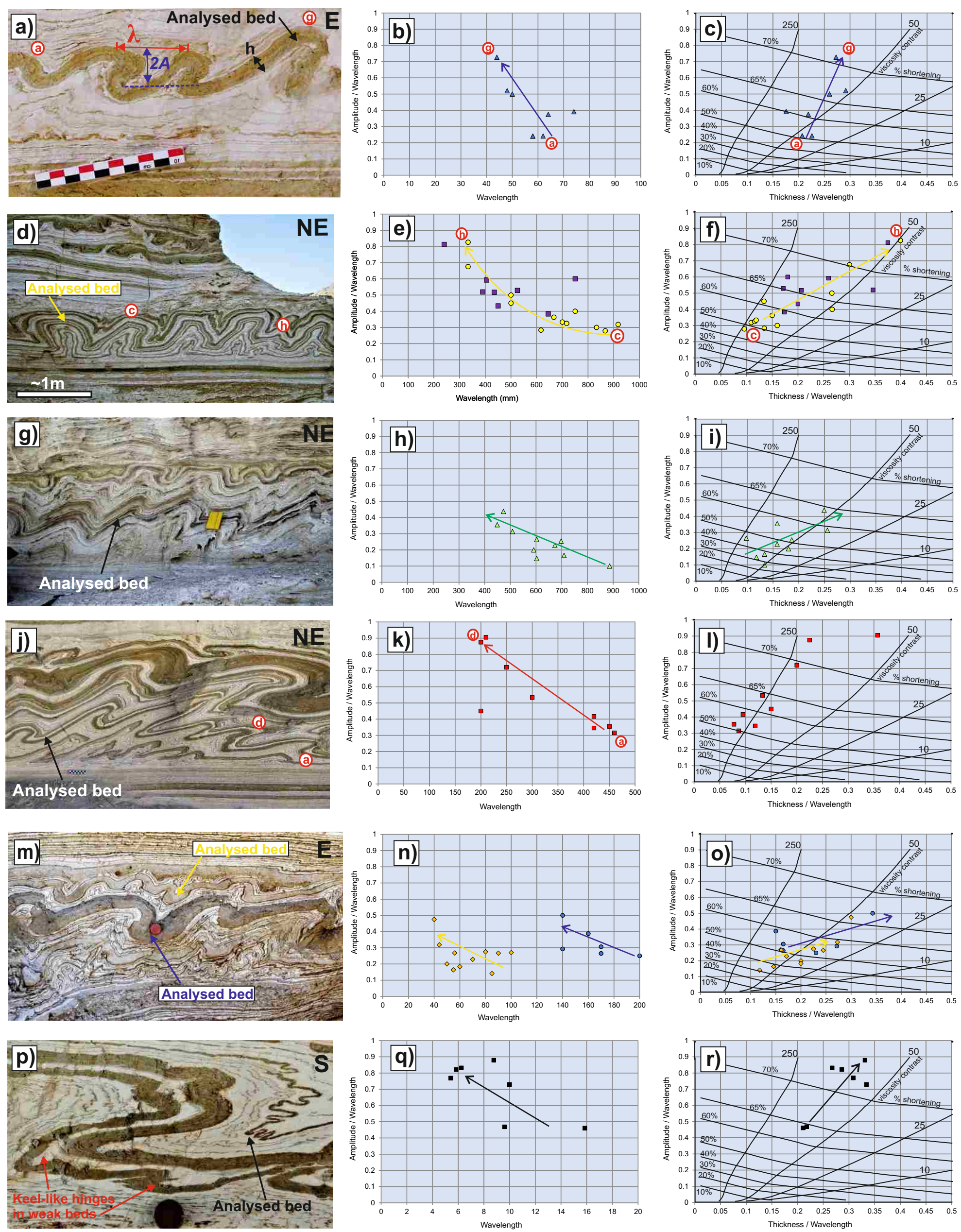

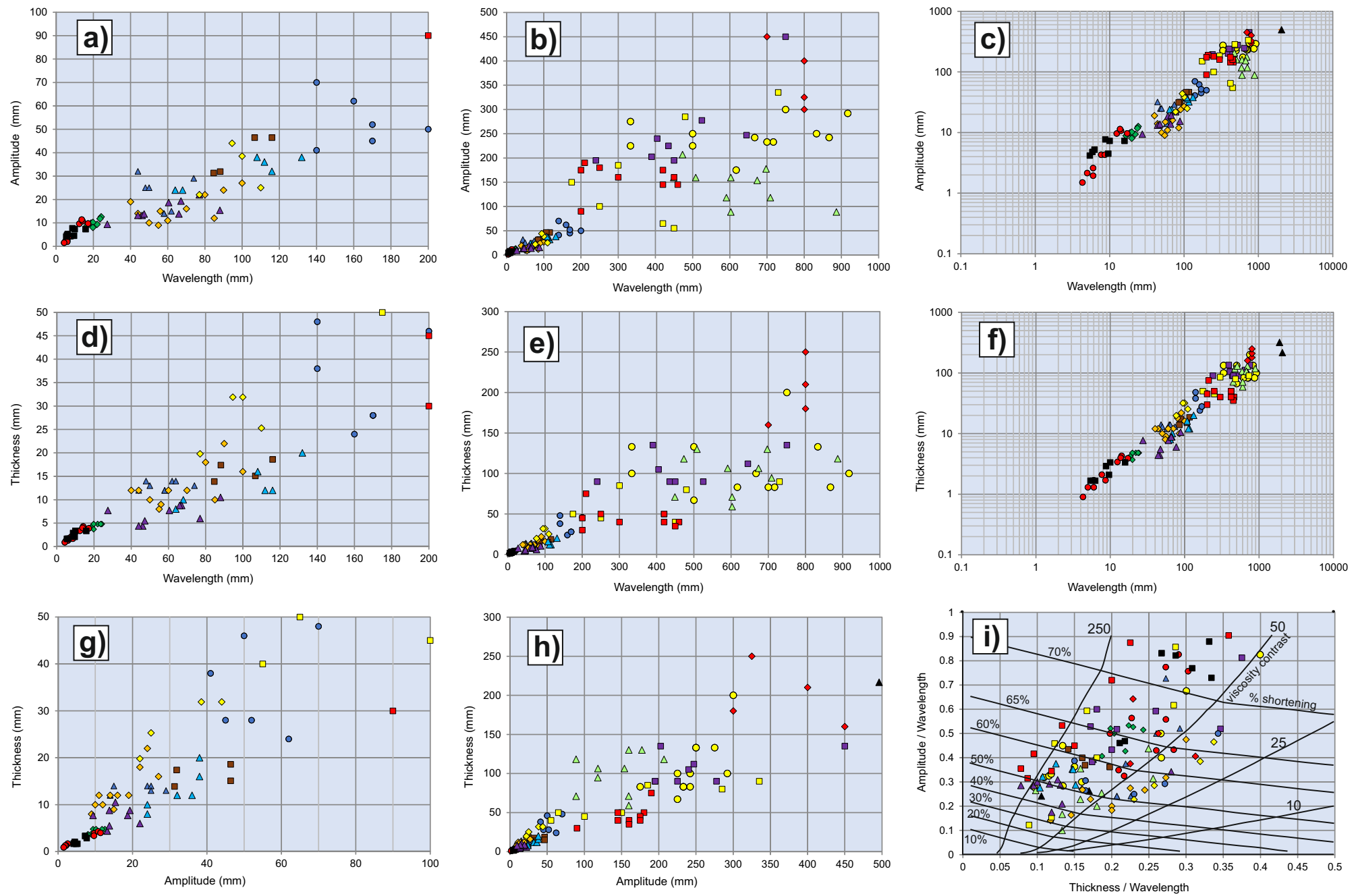


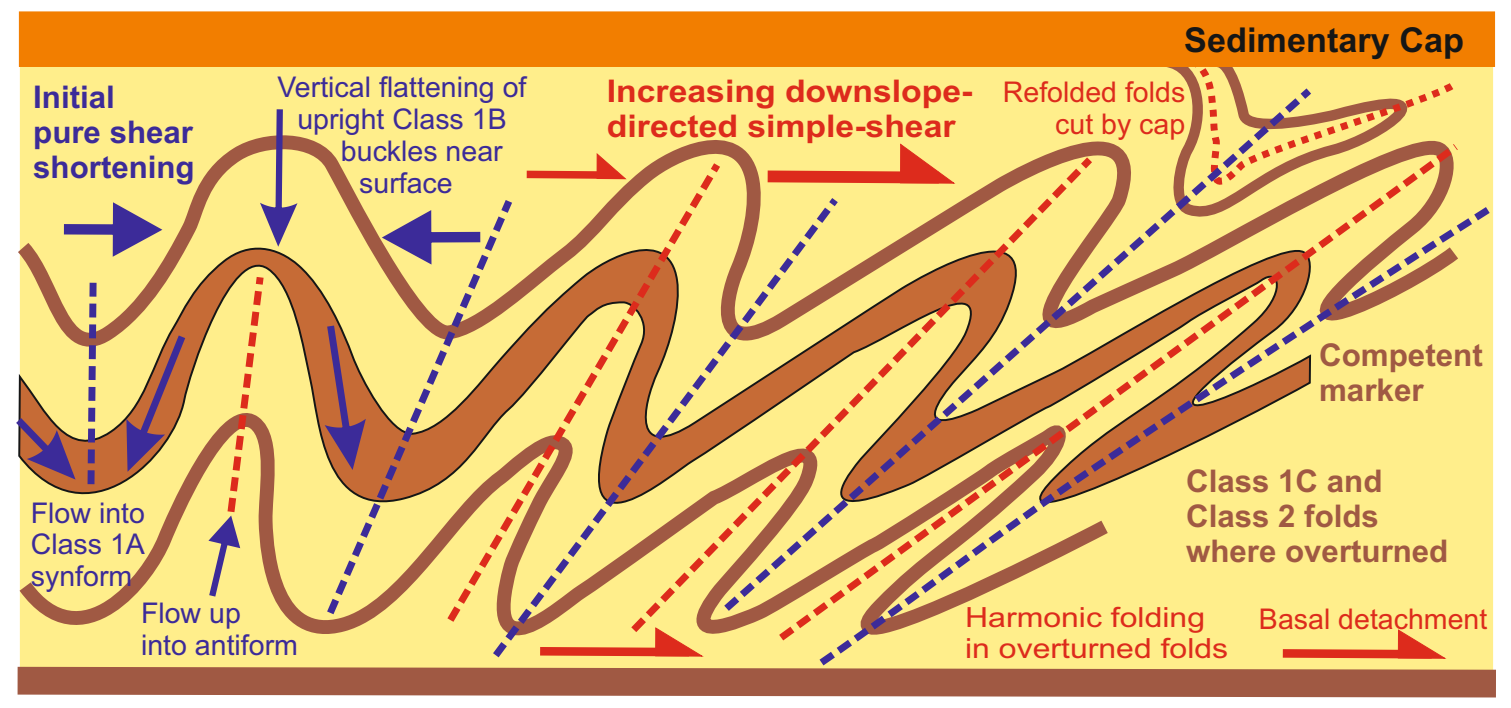

